\title{
Income Differences and Prices of Tradables: Insights from an Online Retailer
}

\author{
Ina Simonovska* \\ University of California, Davis and NBER \\ March, 2015 \\ Forthcoming in Review of Economic Studies
}

\begin{abstract}
I study the positive relationship between prices of tradable goods and per-capita income. I develop a highly tractable general equilibrium model of international trade with heterogeneous firms and non-homothetic consumer preferences that positively links prices of tradables to consumer income. Guided by the model's testable prediction, I estimate the elasticity of price with respect to percapita income from a unique dataset that I construct, which features prices of 245 identical goods sold in 29 European, Asian, and North American markets via the Internet by Spain's second largest apparel manufacturer-Mango. I find that doubling a destination's per-capita income results in an $18 \%$ increase in the price of identical items sold there. Per-capita income differences account for a third, while shipping cost differences can explain up to a third of the cross-country price variations of identical items purchased via the Internet by consumers who do not take advantage of quantity discounts. The price elasticity estimates compare favorably to estimates that I obtain from a standard dataset that features prices across retail locations around the world, suggesting that variable mark-ups play a key role in accounting for observed cross-country differences in prices of tradables.
\end{abstract}

JEL Classification: E31, F12, F14, L11

Keywords: LOP failure, variable mark-ups, non-homothetic preferences, online retail

*I am grateful to my PhD thesis advisors Timothy Kehoe and Fabrizio Perri for their continued guidance and encouragement throughout this project. For their comments and suggestions I especially thank the editor and four anonymous referees, George Alessandria, Cristina Arellano, Costas Arkolakis, John Asker, Klaus Desmet, Robert Feenstra, Marc Melitz, Douglas Miller, Joan Enric Ricart, Michael Waugh, Hakan Yilmazkuday, members of the Trade and Development Workshop at the University of Minnesota and seminar participants at USC, Stanford, Stockholm IIES, NHH, Copenhagen Business School, UC Santa Cruz, AEA 2010, Michigan, Chicago Fed, Temple, Dallas Fed, NBER ITI Summer Institute 2009, SED 2009, North American Summer Meeting of the Econometric Society 2009, Midwest Macro Spring Meeting 2009, Midwest International Economics Spring Meeting 2009, International Comparisons Conference at UC Davis, RES 2009, World Bank, Bank of Canada, UBC, UQAM, Montreal, Adelaide, Melbourne, UI Bloomington, Notre Dame, UT Austin, UC Davis, IMF and Minneapolis Fed. I thank all the participants of the Mango-DHL controlled experiment. I thank the World Bank for providing me with the price data from the 2005 ICP round. Financial support from the Graduate Research Partnership Program Fellowship at the University of Minnesota and the Peter B. Kenen Fellowship at Princeton University are gratefully acknowledged. All remaining errors are mine.

Contact: Department of Economics, University of California, Davis, One Shields Avenue, Davis, California 95616. Email: inasimonovska@ucdavis.edu. 


\section{Introduction}

International trade has grown considerably in the post-war period (see Hummels (2007)). In addition, goods exports continue to account for eighty percent of world exports. ${ }^{1}$ Since tradable goods constitute a high share of consumption bundles of individuals, their prices directly affect consumer welfare. Consequently, studying the underlying mechanisms that shape the behavior of tradable consumption-good prices across countries has been a major focus of research in international trade.

One of the most robust empirical findings in the literature is that prices of tradable consumption goods are higher in countries that are richer in per-capita terms (see Alessandria and Kaboski (2011)). In this paper, I argue that variable mark-ups make a key contribution toward this relationship between prices of tradables and per-capita income. To that end, I develop a tractable general equilibrium model of international trade with heterogeneous firms and non-homothetic consumer preferences over varieties that positively links prices of tradables to consumer income. Guided by the model's testable prediction, I estimate the elasticity of price with respect to per-capita income from a unique dataset that I construct, which features prices of 245 identical goods sold in 29 European, Asian, and North American markets via the Internet by Spain's second largest apparel manufacturer-Mango. I find that doubling a destination's per-capita income results in an $18 \%$ increase in the price of identical items sold there. Per-capita income differences account for a third, while shipping cost differences can explain up to a third of the cross-country price variations of identical items purchased via the Internet by consumers who do not take advantage of quantity discounts. The price elasticity estimates compare favorably to estimates that I obtain from a standard dataset that features prices across retail locations around the world, suggesting that variable mark-ups play a key role in accounting for observed cross-country differences in prices of tradables.

I develop the theory in Section 2. According to the model, trade barriers enable monopolisticallycompetitive firms with varying productivities to supply their products at destination-specific prices. Due to non-homothetic preferences, different per-capita income levels result in different consumption sets across countries. Non-constant expenditure shares yield varying price elasticities of demand for a given positively-consumed variety across destinations. In particular, rich countries' consumers are less responsive to price changes than those of poor ones, so firms optimally price identical varieties higher in more affluent markets. Moreover, firms suffer competitive pressures in more populated markets and extract lower mark-ups there.

In Section 3, I derive a new testable prediction from the model that relates prices to measurable variables. For a pair of countries, the model predicts that the relative price of an identical item varies with the destinations' relative per-capita incomes, trade barriers, and import shares that reflect competition that exporters face across markets. Guided by the prediction, I estimate the elasticity of price with respect to per-capita income from micro-level data in Section 4.

\footnotetext{
${ }^{1}$ World merchandise and service exports for the 2005-2011 period are from the World Development Indicators.
} 
Specifically, I construct a unique price database for the second largest Spanish apparel manufacturer - Mango. The dataset features prices of 245 identical apparel products sold exclusively via the Internet in year 2012 in 29 European, Asian, and North American countries. The empirical focus on "online-only" products in apparel is not accidental. According to a Eurostat survey, in 2012, 75\% of adults in the EU28 used the Internet in the 12 months to the date, of which $60 \%$ indicated that they had shopped online in the same period. The most commonly purchased goods online were clothes and sports goods (32\% in 2012 compared to $21 \%$ in 2008).

Since consumers increasingly acquire apparel via the Internet rather than in physical stores, web prices are particularly relevant for consumer welfare. More importantly, having obtained an in-depth understanding of Mango's online store from the company's website as well as case studies by Kordecka and Ricart (2009) and Pinilla (2007), I am able to identify the sources of crosscountry variations in prices charged by a typical online retailer. First, tracking identical goods enables me to directly measure price discrimination on the basis of varying demand elasticities in the absence of product-quality or production-cost differences. Second, focusing on prices of goods sold exclusively online allows me to suppress destination-specific non-tradable price contributions. Third, since all "online-only" Mango products are stored and dispatched from a single warehouse via DHL Express to every destination, I am able to control for shipping costs in the analysis and hence infer mark-up variations.

Disentangling market-specific costs from mark-ups is the main challenge in studies of price discrimination. In the case of cross-country online sales, there are two distinct problems. First, web-listed prices do not necessarily correspond to actual transaction prices paid by consumers in the presence of shipping and handling charges. Second, shipping and handling charges reflect shipping costs incurred by the retailer as well as mark-ups passed onto consumers, both of which may be destination-specific.

The nature of Mango's online store allows me to tackle both of these issues. To address the first issue, I rely on Mango's shipping and handling policy, which is explicitly described on the company website. Like most online retailers, Mango offers quantity discounts. In particular, Mango's shipping and handling policy is as follows: (i) if a purchase is below a minimum value, then the customer pays an explicit flat shipping fee; (ii) if a purchase is above a minimum value, then the customer pays a lower explicit flat fee (often zero). Both the fees and the minimum value vary by country.

Since the transacted price depends on the type of purchase, I consider three specifications. First, I assume that consumers in each country purchase a single item. In this case, I add the appropriate flat shipping fee depending on whether the item's price is above or below the minimum threshold for each destination. Second, I assume that consumers in each country purchase barely enough products so as to satisfy the respective minimum threshold. Thus, I spread the flat shipping fee for purchases above the threshold over the bundle of goods - namely, I scale the prices of goods by the ad valorem shipping fee. Third, I examine items' prices as listed in the online catalogue. 
To address the second issue, which entails approximating Mango's actual shipping costs, I collect DHL Express shipping prices across destinations. I obtain 'soft evidence' directly from DHL and verify that the company offers percentage discounts to the quoted prices to corporations that carry out multiple shipments. Crucially, these discounts are not destination specific, so they do not affect the relative price that a client pays to ship to different destinations. For example, a client who ships $\$ 1500$ worth of merchandise per month receives a $32 \%$ discount on all shipments regardless of the destination. With this information in mind, I use the collected DHL shipping quotes as proxies for Mango's shipping and handling costs.

Focusing on customers who purchase a single item in each country, after controlling for productspecific fixed effects, DHL shipping costs and return policies by Mango, as well as destinationspecific Spanish market shares (measured in three distinct ways), sales taxes, and tariffs in the apparel and footwear industries, currency-area membership, and income inequality, I find that doubling a destination's per-capita income results in a $14 \%$ increase in the price of identical items sold there. The corresponding statistic is $19 \%$ for web-listed prices and $20 \%$ for prices paid by customers who bundle goods in order to minimize shipping costs.

Across the three specifications, identical items are on average $13 \%$ cheaper in export markets that share a common currency with the manufacturer's country of origin (Spain) and 13\% cheaper in countries where customers enjoy the flexibility to return items in a local physical store. Weblisted prices and prices paid by shipping-cost minimizers do not vary with the cost of shipping, but doubling the DHL shipping cost results in up to a $37 \%$ increase in the price paid by consumers who purchase a single item. This stark difference reflects the fact that shipping charges for a single purchase amount to over a third of a typical item's price. A variance decomposition exercise tells a similar story. Per-capita income differences account for about a third of price variations across the three specifications, while shipping costs account for another third for customers who purchase a single item only. In turn, differences in Mango's return policy across markets and nations' Eurozone membership contribute to less than $15 \%$ and $17 \%$ of the price variation, respectively.

For robustness, I repeat the estimation using five different measures of per-capita income and I add standard geographical and trade-policy proxies for trade barriers employed by the gravity literature. Across 162 different specifications, the median estimated elasticity of price with respect to per-capita income amounts to 0.18. The 5th and 95th percentiles for the estimate are 0.12 and 0.24, respectively. Among the estimates that lie between these two percentiles, having clustered standard errors by destination, all coefficients are statistically significant.

The empirical exercises described above demonstrate that mark-up variations are crucial in accounting for observed differences in prices charged by online retailers across countries. How do price discrimination practices of online retailers compare to those of standard physical retailers? This is a difficult question to answer since prices of identical products from physical outlets are not available for a large set of countries. Alessandria and Kaboski (2011) employ retail prices of aggregate good categories from the International Comparison Program (ICP) database, Crucini and Shintani 
(2008) and Crucini and Yilmazkuday (2014) use retail prices of products with identical characteristics from the Economist Intelligence Unit (EIU) database, while Crucini et al. (2005a) and Crucini et al. (2005b) rely on a similar database for the EU countries for the 1975-1990 period, Goldberg and Verboven (2001) and Goldberg and Verboven (2005) track car prices in Europe, and Ghosh and Wolf (1994) and Haskel and Wolf (2001) examine prices of the Economist magazine and IKEA products, respectively. However, as Burstein et al. (2003) and Crucini and Yilmazkuday (2014) argue, retail data reflect the contributions of non-tradable inputs, whose prices vary systematically with countries' per-capita income levels. Consequently, retail prices of tradables may be linked to countries' per-capita income levels through the contributions of non-tradable channels, making it difficult to separately identify mark-up from local cost components. ${ }^{2}$

In Section 5.1, I compare the estimates of the elasticity of price with respect to per-capita income for Mango products to estimates that I obtain using the ICP database. In the first exercise, I use prices for all tradables as well as for apparel and footwear separately from the ICP database, which spans all the countries that appear in the Mango dataset. I find that the same key variables account for price variations in both the Mango and the ICP data. Turning to magnitudes, similar regression exercises to the ones described above yield median elasticity estimates of 0.26 and 0.12 for tradable goods and apparel products, respectively. The estimates bound the ones obtained for Mango products sold via the Internet, although the statistics reflect different mechanisms. The price elasticity in ICP data may reflect differences in product quality, retail margins, and producers' mark-ups, while the one in the Mango data accounts for producers' mark-ups alone.

Finally, in Section 5.2, I examine whether the patterns documented for the 29 countries above hold more generally around the world. In particular, I rely on the empirical model described above to study sources of price differences across 54 countries in the ICP dataset for which all variables are available, and I expand the analysis to as many as 107 countries for which only sales tax data are lacking. For the set of 54 countries, the median elasticity estimates fall within a very narrow range of 0.18 to 0.21 for tradable goods and apparel products, respectively; for the larger and very diverse set of 107 countries, I find median elasticity estimates of 0.13 and 0.19 for tradables and apparel, respectively. These statistics are remarkably close to the one that I obtain for apparel products sold by Mango via the Internet. Overall, the robustness of the magnitude of the elasticity of price with respect to income across different sets of countries yields strong support toward the role that variable mark-ups play in generating a positive relationship between income and prices

\footnotetext{
${ }^{2}$ To suppress retail components, Hummels and Klenow (2005), Hummels and Lugovskyy (2009), Bastos and Silva (2010), Gorg et al. (2010), Alessandria and Kaboski (2011), Baldwin and Harrigan (2011), Harrigan et al. (2011), Johnson (2012), and Manova and Zhang (2012) use free-on-board unit values to show that importers with high per-capita income levels pay high prices for imports from a given source. The observation may reflect two distinct mechanisms: (i) rich importers demand goods of high quality, as postulated by Verhoogen (2008) and Fajgelbaum et al. (2011); and (ii) exporters extract high mark-ups for identical goods from rich importers with low demand elasticities, as argued in the present paper. While the empirical literature has verified the varying-quality hypothesis, it has been unable to test the presence of variable mark-ups across countries due to the lack of price data of identical goods. In this paper, I aim to fill this gap.
} 
of tradables around the world.

The empirical results that I obtain provide support for a theory of varying demand elasticities, and therefore variable mark-ups. To derive the testable predictions that guide the empirical analysis, I develop a monopolistic competition model with firms that differ in productivity levels and consumers whose preferences and non-homothetic. In particular, I employ a utility function that belongs to the hierarchic-demand class studied by Jackson (1984). Two additional utility functions of this class have been recently introduced to the international-trade literature that features firm heterogeneity. The first is the linear demand system used by Melitz and Ottaviano (2008) and the second is the exponential (CARA) utility used by Behrens et al. (2014). Both frameworks yield identical qualitative predictions as the present model regarding the behavior of prices within a country. An advantage of the utility parametrization that I introduce is that it maintains tractability in general equilibrium and it is especially useful for cross-country empirical analysis. With this in mind, I begin by describing the model.

\section{Model}

\subsection{Consumer Problem}

I consider a world that is made up of a finite number of countries, $I$, engaged in trade of varieties of a final good. Let $i$ represent an exporter and $j$ an importer.

I assume that country $j$ is populated by identical consumers of measure $L_{j}$ who have preferences over varieties of a good. Varieties originating from different countries enter symmetrically in a consumer's utility function according to the following rule

$$
U_{j}^{c}=\sum_{i=1}^{I} \int_{\omega \in \Omega_{i j}} \log \left(q_{i j}^{c}(\omega)+\bar{q}\right) d \omega,
$$

where $q_{i j}^{c}(\omega)$ is individual consumption of variety $\omega$ from country $i$ in $j$ and $\bar{q}>0$ is a (noncountry-specific) constant. To ensure that the utility function is well defined, I assume that, for all $j, \Omega_{j} \equiv \sum_{i=1}^{I} \Omega_{i j} \subseteq \bar{\Omega}$, where $\bar{\Omega}$ is a compact set containing all potentially-produced varieties.

The demand for variety $\omega$ originating from $i$ that is consumed in a positive amount in $j$, $q_{i j}(\omega)>0$, is given by $^{3}$

$$
q_{i j}(\omega)=L_{j}\left\{\frac{y_{j}+\bar{q} P_{j}}{N_{j} p_{i j}(\omega)}-\bar{q}\right\} .
$$

\footnotetext{
${ }^{3}$ See Appendix A.1 for statement of and solution to consumer problem.
} 
In expression (1), $y_{j}$ is consumer income and $N_{j}$ is the total measure of varieties consumed in $j$,

$$
N_{j}=\sum_{i=1}^{I} N_{i j}
$$

where $N_{i j}$ is the measure of the set $\Omega_{i j}$, which contains varieties originating from $i$. Furthermore, $P_{j}$ is an aggregate price statistic summarized by

$$
P_{j}=\sum_{i=1}^{I} \int_{\omega \in \Omega_{i j}} p_{i j}(\omega) d \omega
$$

Several properties of consumer demand are worth noting. The preference relation described above is non-homothetic. Moreover, the marginal utility from consuming a variety, $\left(q_{i j}^{c}(\omega)+\bar{q}\right)^{-1}$, is bounded from above at any level of consumption. Hence, a consumer does not have positive demand for all varieties. From the consumer demand in equation (1), let $p_{j \max } \equiv\left(y_{j}+\bar{q} P_{j}\right) / \bar{q} N_{j}$ be the price at which demand for a variety in country $j$ is driven to 0 . This reservation price is lower in more competitive environments where the aggregate price statistic $P_{j}$ is lower or the measure of available varieties $N_{j}$ is higher. In addition, all else equal, an increase in income $y_{j}$ raises the reservation price, so consumers are willing to expand their consumption sets. Finally, the (absolute value of the) price elasticity of demand for variety $(\omega, i)$ in $j, \epsilon_{i j}(\omega)=\left[1-\left(p_{i j}(\omega) / p_{j \max }\right)\right]^{-1}$, is falling in the reservation price. Thus, higher consumer income and lower competition make consumers less sensitive to price changes, which has implications about the price-setting behavior of firms in such markets. With this in mind, I turn to describe the firm's problem next.

\subsection{Firm Problem}

The environment is static. Each variety is produced by a single firm using constant-returns-to-scale technology. Labor is the only factor of production. Following Melitz (2003), I assume that firms differ in their productivity, $\phi$, and country of origin, $i$.

In every country $i$, there exists a pool of potential entrants who pay a one-time cost, $f_{e}>0$, which entitles them to a single productivity draw from a distribution, $G_{i}(\phi)$, with support $\left[b_{i}, \infty\right)$. A measure $J_{i}$ of firms that are able to cover their marginal cost of production enter. However, only

a subset of productive entrants, $N_{i j}$, produce and sell to market $j$. These firms are able to charge a low enough price so as to generate non-negative demand in expression (1), while making nonnegative profits. Thus, a subset of entrants immediately exit. Hence, in equilibrium, the expected profit of an entrant is zero. Aggregate profit rebates to each consumer are therefore also zero. Assuming that each consumer has a unit labor endowment-which, when supplied (inelastically) to the local labor market earns a wage rate of $w_{j}$ - per-capita income necessarily equals $w_{j}$.

Having described the market structure, I proceed to set up an operating firm's maximization 
problem. Let the production function of a firm with productivity draw $\phi$ be $x(\phi)=\phi l$, where $l$ is the amount of labor used toward the production of final output. Moreover, assume that each firm from country $i$ wishing to sell to destination $j$ faces an iceberg transportation cost incurred in terms of labor units, $\tau_{i j} \geq 1$, with $\tau_{i i}=1(\forall i)$. An operating firm must choose the price of its variety $p$, accounting for the demand for its product $q$. I consider a symmetric equilibrium where all firms of type $\phi$ from $i$ choose identical optimal pricing rules. Thus, I can index each variety by the productivity and the country of origin of its producer, which allows me to rewrite individual consumer and country demand as follows

$$
\begin{aligned}
q_{i j}^{c}(\phi) & =\frac{w_{j}+\bar{q} P_{j}}{N_{j} p_{i j}(\phi)}-\bar{q}, \\
q_{i j}(\phi) & =L_{j}\left\{\frac{w_{j}+\bar{q} P_{j}}{N_{j} p_{i j}(\phi)}-\bar{q}\right\} .
\end{aligned}
$$

Using demand from (5), the profit maximization problem of a firm with productivity $\phi$ from country $i$ that is considering to sell to destination $j$ becomes

$$
\pi_{i j}(\phi)=\max _{p_{i j} \geq 0} p_{i j} L_{j}\left\{\frac{w_{j}+\bar{q} P_{j}}{N_{j} p_{i j}}-\bar{q}\right\}-\frac{\tau_{i j} w_{i}}{\phi} L_{j}\left\{\frac{w_{j}+\bar{q} P_{j}}{N_{j} p_{i j}}-\bar{q}\right\} .
$$

To solve this problem, each firm takes as given the measure of competitors $N_{j}$ and the aggregate price statistic $P_{j}$. Taking first-order conditions, the resulting optimal price that a firm charges for its variety which is supplied in a positive amount is given by

$$
p_{i j}(\phi)=\left(\frac{\tau_{i j} w_{i}}{\phi} \frac{w_{j}+\bar{q} P_{j}}{N_{j} \bar{q}}\right)^{\frac{1}{2}}
$$

\subsection{Productivity Thresholds and Firm-Level Mark-Ups}

As noted earlier, in this model, not all firms serve all destinations. In particular, for any pair of source and destination countries, $i$ and $j$, only firms originating from country $i$ with productivity draws $\phi \geq \phi_{i j}^{*}$ sell to market $j$, where $\phi_{i j}^{*}$ is a productivity threshold defined by ${ }^{4}$

$$
\phi_{i j}^{*}=\sup _{\phi \geq b_{i}}\left\{\pi_{i j}(\phi)=0\right\}
$$

Thus, a productivity threshold is the productivity draw of a firm that is indifferent between serving a market or not, namely one whose variety's price barely covers the firm's marginal cost of production and delivery,

$$
p_{i j}\left(\phi_{i j}^{*}\right)=\frac{\tau_{i j} w_{i}}{\phi_{i j}^{*}}
$$

\footnotetext{
${ }^{4}$ I restrict $f_{e}$ to ensure that $b_{i} \leq \phi_{i j}^{*}(\forall i, j)$.
} 
The price that a firm would charge for its variety, however, is limited by the variety's demand, which diminishes as the variety's price rises. In particular, it is the case that consumers in destination $j$ are indifferent between buying the variety of type $\phi_{i j}^{*}$ or not. To see this, from (5), notice that consumers' demand is exactly zero for the variety whose price satisfies

$$
p_{i j}\left(\phi_{i j}^{*}\right)=\frac{w_{j}+\bar{q} P_{j}}{N_{j} \bar{q}}
$$

Combining expressions (8) and (9) yields a simple characterization of the threshold

$$
\phi_{i j}^{*}=\frac{\tau_{i j} w_{i} N_{j} \bar{q}}{w_{j}+\bar{q} P_{j}}
$$

Substituting (10) in (7), the optimal pricing rule of a firm with productivity draw $\phi \geq \phi_{i j}^{*}$ becomes

$$
p_{i j}(\phi)=\underbrace{\left(\frac{\phi}{\phi_{i j}^{*}}\right)^{\frac{1}{2}}} \underbrace{\frac{\tau_{i j} w_{i}}{\phi}} .
$$

mark-up marginal cost

Expression (11) shows that mark-ups vary along two dimensions in this model. First, more productive firms charge higher mark-ups over marginal cost. This prediction is in line with the behavior of Slovenian manufacturers, as documented by De Loecker and Warzynski (2012). Second, firms' prices and mark-ups vary systematically with market characteristics, which are summarized by the threshold that firms must surpass in order to serve a destination. The thresholds are, in turn, equilibrium objects. Consequently, I proceed to characterize the equilibrium of the model.

\subsection{Equilibrium of the World Economy}

The subset of entrants from $i$ who surpass the productivity threshold $\phi_{i j}^{*}$ serve destination $j$. These firms, denoted by $N_{i j}$, satisfy

$$
N_{i j}=J_{i}\left[1-G_{i}\left(\phi_{i j}^{*}\right)\right]
$$

Let $g_{i}(\phi)$ be the pdf corresponding to the productivity cdf $G_{i}(\phi)$. Then, the conditional density of firms operating in $j$ is

$$
\mu_{i j}(\phi)= \begin{cases}\frac{g_{i}(\phi)}{1-G_{i}\left(\phi_{i j}^{*}\right)} & \text { if } \phi \geq \phi_{i j}^{*} \\ 0 & \text { otherwise }\end{cases}
$$


With these definitions in mind, the aggregate price statistic in (3) can be rewritten as

$$
P_{j}=\sum_{i=1}^{I} N_{i j} \int_{\phi_{i j}^{*}}^{\infty} p_{i j}(\phi) \mu_{i j}(\phi) d \phi .
$$

Using the above objects, total sales to country $j$ by firms originating from country $i$ become

$$
T_{i j}=N_{i j} \int_{\phi_{i j}^{*}}^{\infty} p_{i j}(\phi) x_{i j}(\phi) \mu_{i j}(\phi) d \phi .
$$

Furthermore, individual firm profits are the sum of profit flows from each destination that a firm sells to. Hence, the average profits of firms originating from country $i$ are

$$
\pi_{i}=\sum_{j=1}^{I}\left[1-G_{i}\left(\phi_{i j}^{*}\right)\right] \int_{\phi_{i j}^{*}}^{\infty} \pi_{i j}(\phi) \mu_{i j}(\phi) d \phi,
$$

where potential profits from destination $j$ are weighted by the probability that they are realized, $1-G_{i}\left(\phi_{i j}^{*}\right)$. Due to free entry, the average profit, in turn, barely covers the fixed cost of entry

$$
w_{i} f_{e}=\sum_{j=1}^{I}\left[1-G_{i}\left(\phi_{i j}^{*}\right)\right] \int_{\phi_{i j}^{*}}^{\infty} \pi_{i j}(\phi) \mu_{i j}(\phi) d \phi
$$

Finally, $i$ 's consumers' income, spent on final goods that are produced at home and abroad, is

$$
w_{i} L_{i}=\sum_{j=1}^{I} T_{j i}
$$

Equilibrium. For $i, j=1, \ldots, I$, given $\tau_{i j}, L_{j}, b_{i}, f_{e}, \bar{q}$, and productivity distributions $G_{i}(\phi)$, an equilibrium is a set of total measures of firms serving $j \hat{N}_{j}$; productivity thresholds $\hat{\phi}_{i j}^{*}$; measures of firms from $i$ serving $j \hat{N}_{i j}$; conditional densities of firms from $i$ serving $j \hat{\mu}_{i j}(\phi)$; aggregate price statistics $\hat{P}_{j}$; total sales of firms from $i$ serving $j \hat{T}_{i j}$; wage rates $\hat{w}_{i}$; measures of entrants $\hat{J}_{i}$; and, $\forall \phi \in\left[\phi_{i j}^{*}, \infty\right)$, per-consumer allocations $\hat{q}_{i j}^{c}(\phi)$, country allocations $\hat{q}_{i j}(\phi)$, firm pricing rules $\hat{p}_{i j}(\phi)$, firm production rules $\hat{x}_{i j}(\phi)$, and firm profits $\hat{\pi}_{i j}(\phi)$, such that: (i) $\hat{q}_{i j}^{c}(\phi)$ is given by (4) and solves the individual consumer's problem; (ii) $\hat{q}_{i j}(\phi)$ is given by (5) and satisfies a country's aggregate demand for a variety; (iii) $\hat{p}_{i j}(\phi)$ is given by $(7)$ and solves the firm's problem; (iv) $\hat{x}_{i j}(\phi)$ satisfies goods' markets clearing $\hat{q}_{i j}(\phi)=\hat{x}_{i j}(\phi) ;(\mathrm{v}) \hat{\pi}_{i j}(\phi)$ is given by $(6) ;(\mathrm{vi}) \hat{N}_{j}, \hat{\phi}_{i j}^{*}, \hat{N}_{i j}, \hat{\mu}_{i j}(\phi), \hat{P}_{j}, \hat{T}_{i j}$, $\hat{w}_{i}, \hat{J}_{i}$ jointly satisfy $(2),(10),(12),(13),(14),(15),(16)$, and (17). 


\section{Model Predictions}

In this section, I describe the model's predictions regarding the behavior of firms within and across countries. First, I discuss the entry decisions of firms across markets, which sets the stage for the discussion on price discrimination. Second, I derive novel predictions regarding the firms' pricing decisions across countries. Third, I discuss supplementary predictions on the sales of exporters, which help place the model in an empirical context.

In order to analytically solve the model and to derive stark predictions at the firm and aggregate levels, I follow Chaney (2008) and assume that firm productivities are drawn from a Pareto distribution with cdf $G_{i}(\phi)=1-b_{i}^{\theta} / \phi^{\theta}$, pdf $g_{i}(\phi)=\theta b_{i}^{\theta} / \phi^{\theta+1}$, and shape parameter $\theta>1$. The support of the distribution is $\left[b_{i}, \infty\right)$, where $b_{i}$ summarizes the level of technology in country $i{ }^{5}$ Moreover, varying levels of technology are related to per-capita income differences across countries. In particular, a relatively high $b_{i}$ represents a more technologically-advanced country. Such a country is characterized by relatively more productive firms, whose marginal costs of production are low, and by richer consumers, who enjoy higher wages. ${ }^{6}$

\subsection{Firm Entry}

In this model, only the most productive subset of domestic entrants serves the foreign destinations, as long as trade barriers are sufficiently high. From expression (12), under the assumption that firm productivities are Pareto-distributed, the subset of entrants from country $i$ who serve market $j$ is inversely related to the productivity threshold $\phi_{i j}^{*}$ and given by $L_{i} b_{i}^{\theta}\left[(\theta+1) f_{e}\left(\phi_{i j}^{*}\right)^{\theta}\right]^{-1}$, where ${ }^{7}$

$$
\phi_{i j}^{*}=\frac{\bar{q}^{\frac{1}{\theta+1}} \tau_{i j} w_{i}}{\left[(\theta+1) f_{e}(1+2 \theta) w_{j}\right]^{\frac{1}{\theta+1}}}\left\{\sum_{v=1}^{I} \frac{L_{v} b_{v}^{\theta}}{\left(\tau_{v j} w_{v}\right)^{\theta}}\right\}^{\frac{1}{\theta+1}} .
$$

The productivity threshold for firms from source $i$ to sell to destination $j$ depends on three sets of parameters: (i) economy-wide parameters $\left(f_{e}, \theta, \bar{q}\right)$; (ii) trade costs and per-capita income levels of the pair of countries $\left(\tau_{i j}, w_{i}, w_{j}\right)$; (iii) general equilibrium object $\left(\sum_{v=1}^{I} L_{v} b_{v}^{\theta}\left(\tau_{v j} w_{v}\right)^{-\theta}\right)$. Looking at comparative statics, the last term suggests that the larger and the more productive any country is, the higher is the productivity threshold to access a given destination $j$. For a given entry cost, larger markets allow for more domestic entrants, thus raising the total number of firms in the world economy and generating tougher competition for any firm in any market. Similarly, higher expected productivities of average entrants in any country give rise to tougher competition in the

\footnotetext{
${ }^{5}$ Since the unconditional mean of the Pareto distribution is $b_{i} \theta /(\theta-1)$, a ratio of $b_{i}$ 's reflects the relative (unconditional) mean productivities of two countries. All predictions derived in the remainder of the paper are identical if instead I set $b_{i}=b_{j}=b$ for all $i \neq j$ and let firms' production functions be $x_{i}(\phi)=A_{i} \phi l$, where $A_{i}$ is country-specific total factor productivity.

${ }^{6}$ In Appendix A.2, I show that, in general equilibrium, a relative increase in $b_{i}$ increases the relative wage in $i$.

${ }^{7}$ See Appendix A.2 for derivations.
} 
world economy for any firm.

Unlike market size and productivity, trade costs and per-capita income levels of different countries have differing effects on productivity thresholds. For exporter $i$ and importer $j$, a relative increase in the exporter's wage rate or trade cost to destination $j$ raises the productivity threshold that firms from $i$ need in order to access market $j$. The intuition for this result is simple: the higher is the relative wage rate or trade barrier of an exporting country, the higher is the marginal cost that the firms originating from that country face, relative to other exporters. Consequently, firms from $i$ need a higher productivity level in order to reach destination $j$. Increases in the marginal cost of production of any other potential exporter to market $j$ on the other hand lower the productivity threshold for firms from $i$.

Finally, a key characteristic that determines firm access to a destination is the market's percapita income level. A rise in $w_{j}$ lowers the threshold in (18), thus raising the measure of entrants there. The result is an artifact of the "bounded marginal utility" property of consumer preferences. Since the marginal utility of any variety is bounded from above at any level of consumption, the consumer spends her limited income on the subset of potentially-produced items whose prices do not exceed the reservation price. An increase in an individual's income raises the reservation price making new varieties desriable and the consumer expands her consumption bundle. Hence, the model yields a positive link between countries' per-capita incomes and the set of purchased, including imported, varieties, which is in line with empirical findings by Jackson (1984), Hunter and Markusen (1988), Hunter (1991), Movshuk (2004), and Hummels and Klenow (2005).

Overall, country characteristics systematically affect productivity thresholds and consequently the measure of competitors in each destination. These pro-competitive effects directly translate into varieties' prices, which I examine next.

\subsection{Price Discrimination}

In this section, I discuss the predictions of the model regarding the variation of relative prices of identical items with respect to key country characteristics. Appendix A.3 contains the proofs.

Expression (11) showed that firm mark-ups across markets depend inversely on the productivity thresholds of the destinations. Moreover, the previous section demonstrates that the threshold is a decreasing function of the per-capita income of the destination. Hence, a rise in the per-capita income in a market raises the price of a variety sold there.

The intuition behind the result lies in the relationship between the elasticity of substitution across varieties and consumer income. Recall that agents expand their consumption bundles when their income rises, as discussed above. However, a rise in consumer income also increases the consumption of each positively-consumed variety. To see this, substitute (10) and (11) into (4) to 
obtain the following expression for an individual's consumption of an item

$$
q_{i j}^{c}(\phi)=\bar{q}\left[\left(\frac{\phi}{\phi_{i j}^{*}}\right)^{\frac{1}{2}}-1\right]
$$

The right-hand side of expression (19) falls in the cutoff productivity, so the quantity consumed rises in individual income. But, variations in consumption change elasticities of substitution and consequently affect prices of varieties. The elasticity of substitution for any two positively-consumed varieties in $j$, that are produced by firms with productivities $\phi_{1}$ and $\phi_{2}$, which originate from countries $i$ and $i^{\prime}$ respectively, is

$$
\sigma_{q_{i j}^{c}\left(\phi_{1}\right), q_{i^{\prime} j}^{c}\left(\phi_{2}\right)}=1+\frac{\bar{q}}{2}\left[\frac{1}{q_{i j}^{c}\left(\phi_{1}\right)}+\frac{1}{q_{i^{\prime} j}^{c}\left(\phi_{2}\right)}\right] .
$$

As the consumer becomes richer, she consumes more of each variety, which drives down the elasticity of substitution between positively-consumed varieties. Prices of these varieties rise in response.

Another intuitive explanation of the price increase due to higher income involves ordering varieties according to their "importance" to the consumer. As consumer income rises, new varieties produced by less productive firms are added to the consumption set. Conversely, if individual income were to fall, the new varieties are the first to be dropped from a consumer's bundle. Thus, the preference relation is "hierarchic" - a term introduced to the consumer-choice literature by Jackson (1984). The newly-added varieties are less important than the previously-consumed ones, which results in a fall in the demand elasticities of the latter. Hence, as income rises, prices of all previously-consumed varieties also rise.

To see this, from (11) and (19), note that the (absolute value of the) price elasticity of demand for variety $(\phi, i)$ in $j$ is

$$
\epsilon_{i j}(\phi)=\left[1-\left(\frac{\phi}{\phi_{i j}^{*}}\right)^{-\frac{1}{2}}\right]^{-1}
$$

If the per-capita income in market $j$ rises, the productivity threshold falls. According to expression (20), the demand for a variety becomes less elastic. However, the elasticity of demand is reflected in the price of the item, which can be seen by combining expressions (11) and (20) to obtain

$$
p_{i j}(\phi)=\frac{\tau_{i j} w_{i}}{\phi} \frac{\epsilon_{i j}(\phi)}{\epsilon_{i j}(\phi)-1}
$$

As consumer income rises, demand becomes less elastic, which allows firms to raise their prices.

Having described the behavior of prices within a country, it is easy to understand how prices of identical items vary across countries. Consider a firm with productivity $\phi$, originating from $i$ 
and selling an identical variety to markets $j$ and $k$, that is, $\phi \geq \max \left[\phi_{i j}^{*}, \phi_{i k}^{*}\right]$. Using expressions (11) and (18), the relative price that this firm charges across the two markets is given by

$$
\frac{p_{i j}(\phi)}{p_{i k}(\phi)}=\underbrace{\left(\frac{w_{j}}{w_{k}}\right)^{\frac{1}{2(\theta+1)}}}_{\text {pc income }} \underbrace{\left(\frac{\tau_{i j}}{\tau_{i k}}\right)^{\frac{1}{2}}}_{\text {trade cost }} \underbrace{\left(\frac{\sum_{v} L_{v} b_{v}^{\theta}\left(\tau_{v j} w_{v}\right)^{-\theta}}{\sum_{v} L_{v} b_{v}^{\theta}\left(\tau_{v k} w_{v}\right)^{-\theta}}\right)^{-\frac{1}{2(\theta+1)}}}_{\text {general equilibrium object }} .
$$

The relative per-capita income levels of the two countries have opposing effects on the relative price of an identical item across destinations. The first term in expression (22) suggests that a relative increase in country $j$ 's per-capita income (keeping country $k$ 's per-capita income unchanged) raises the relative price of the variety there. This direct effect of per-capita income on prices is due to the assumed non-homotheticity in consumer preferences discussed above. However, the relative rise of country $j$ 's per-capita income affects prices via the general equilibrium object in expression (22) as well. To get intuition on this object, it is useful to derive the bilateral trade or market shares. First, multiply (19) by the destination's size $L_{j}$ to obtain the quantity sold in $j$ by a firm with productivity $\phi$ from $i$. To derive $i$ 's total sales in $j$, substitute this quantity, as well as the price from (11), the conditional density from (13) under the Pareto parametrization, and the measure of exporters from the previous subsection into expression (15). Then, using expression (18) and the fact that $\tau_{i j} w_{i} / \phi_{i j}^{*}=\tau_{j j} w_{j} / \phi_{j j}^{*}(\forall i \neq j)$ (which is apparent in expression (10)), the import share of $i$-goods in $j$ can be defined as

$$
\lambda_{i j} \equiv \frac{T_{i j}}{\sum_{v=1}^{I} T_{v j}}=\frac{L_{i} b_{i}^{\theta}\left(\tau_{i j} w_{i}\right)^{-\theta}}{\sum_{v=1}^{I} L_{v} b_{v}^{\theta}\left(\tau_{v j} w_{v}\right)^{-\theta}} .
$$

Finally, substitute (23) into (22) to obtain the following testable prediction that links relative prices to measurable variables

$$
\frac{p_{i j}(\phi)}{p_{i k}(\phi)}=\underbrace{\left(\frac{w_{j}}{w_{k}}\right)^{\frac{1}{2(\theta+1)}}}_{\text {pc income }} \underbrace{\left(\frac{\tau_{i j}}{\tau_{i k}}\right)^{\frac{2 \theta+1}{2(\theta+1)}}}_{\text {trade cost }} \underbrace{\left(\frac{\lambda_{i j}}{\lambda_{i k}}\right)^{\frac{1}{2(\theta+1)}}}_{\text {market share }} .
$$

The third object above suggests that the relative price of a given variety from source $i$ in two countries is increasing in the relative market shares of firms from $i$ in the two destinations. The per-capita income levels of the countries in turn affect these market shares. An increase in country $j$ 's per-capita income (keeping country $k$ 's per-capita income unchanged) raises the marginal cost of production of firms from country $j$ making them less competitive on the world market. As a result, firms from other countries gain world market shares. In particular, firms originating from country $i$ increase their market shares in both destinations $j$ and $k$. If the increase in market share 
in $j$ is at least as large as in $k$, then the effect of relative per-capita income increases on relative prices via market shares is non-negative. A sufficient condition to ensure that relative market shares are non-decreasing in relative per-capita incomes of destinations is that trade barriers obey the triangle inequality. Proposition 1 below summarizes the result.

Proposition 1. If trade barriers obey the triangle inequality, $(\forall j, k, v) \tau_{v j} \tau_{j k} \geq \tau_{v k}$, then the relative price of a variety sold in two markets is strictly rising in the markets' relative per-capita incomes.

Intuitively, for a given variety that is sold in two markets, the consumers in the rich country are less responsive to price changes than the consumers in the poor one. A firm exploits this opportunity, amid trade barriers that segment the markets, and charges a high mark-up in the affluent destination.

Before engaging in empirical analysis, it is important to note from expression (23) that destinations' population sizes affect market shares. Consider an increase in the population size of country $j$, while keeping $k$ 's characteristics fixed. Then, the measure of entrants from $j$ increases, which strengthens competition, thus reducing the market shares of other countries. In particular, firms originating from country $i$ experience a fall in their market shares in both destinations $j$ and $k$. If the fall in market share in $j$ is at least as large as in $k$, then the effect of relative population size increases on relative prices via market shares is non-positive. A sufficient condition to ensure that relative market shares are non-increasing (strictly decreasing) in relative population sizes of destinations is that trade barriers obey the triangle inequality (strictly for at least one source country). Proposition 2 below summarizes the result.

Proposition 2. Given relative per-capita income levels, for any two countries, $j$ and $k, j \neq k$, if trade barriers obey the triangle inequality, $(\forall v) \tau_{v j} \tau_{j k} \geq \tau_{v k}$, and if the inequality for at least one $v \neq j$ is strict, then the relative price of a variety sold in markets $j$ and $k$ is strictly decreasing in the relative population sizes of the markets.

To summarize, in this model, trade barriers, per-capita income levels, and market shares shape prices across countries. In particular, the relative price of a given variety in a pair of countries is increasing in the relative trade barriers and per-capita income levels of the two destinations. Furthermore, the relative price is increasing in the relative market shares of the exporting country in the two destinations. Destination per-capita income and population size, in turn, affect relative prices indirectly via market shares. If trade barriers obey the (strict) triangle inequality, relative market shares, and therefore relative prices, are (strictly) increasing in relative per-capita incomes and (strictly) decreasing in relative population sizes of the two destinations. ${ }^{8}$

Finally, since mark-ups are destination-specific in this model, it is worth pointing out the differences between prices that are inclusive of trade costs, such as the ones described above, and

\footnotetext{
${ }^{8}$ Note that, since per-capita income also directly affects prices, a weak triangle inequality is in fact sufficient to ensure that relative prices are strictly rising in relative per-capita incomes.
} 
free-on-board (FOB) prices, which are net of transport costs. Multiplying both sides of expression (24) by $\tau_{i k} / \tau_{i j}$ arrives at relative FOB prices between destinations $j$ and $k$,

$$
\frac{p_{i j}^{f o b}(\phi)}{p_{i k}^{f o b}(\phi)}=\underbrace{\left(\frac{w_{j}}{w_{k}}\right)^{\frac{1}{2(\theta+1)}}}_{\text {pc income }} \underbrace{\left(\frac{\tau_{i j}}{\tau_{i k}}\right)^{-\frac{1}{2(\theta+1)}}}_{\text {trade cost }} \underbrace{\left(\frac{\lambda_{i j}}{\lambda_{i k}}\right)^{\frac{1}{2(\theta+1)}}}_{\text {market share }} .
$$

Clearly, the predictions regarding the effect of relative per-capita incomes and population sizes on relative prices are unchanged. Moreover, it is straightforward to verify that relative FOB prices are decreasing in relative trade barriers. This prediction of the model, however, is not tested in the empirical analysis due to data limitations; in the present dataset, observed prices are inclusive of trade costs and an exact ad valorem measure of trade costs is not available.

\subsection{Firm Sales}

As discussed in Section 3.1, according to this model, only the most productive domestic entrants export. Moreover, ranking export destinations according to their accessibility, which is summarized by the productivity thresholds, implies that more productive firms export to more destinations. To study the sales behavior of each firm, multiply consumer demand in (19) by the destination's size $L_{j}$ to obtain the quantity sold in $j$ by a firm with productivity $\phi$ from $i$, denoted by $x_{i j}(\phi)$. Firm sales per destination are the product of the quantity and the price and are given by

$$
r_{i j}(\phi) \equiv p_{i j}(\phi) x_{i j}(\phi)=\bar{q} L_{j} \frac{\tau_{i j} w_{i}}{\phi_{i j}^{*}}\left[1-\left(\frac{\phi_{i j}^{*}}{\phi}\right)^{\frac{1}{2}}\right]
$$

According to expression (26), firm sales in a destination are falling in the productivity threshold that characterizes the market. From the discussion in Section 3.1, it follows that a firm realizes higher sales in a richer (in per-capita terms) market. However, the effect of country size on firm sales is ambiguous. On the one hand, a more populated market yields more sales. On the other hand, larger markets are more competitive and therefore the productivity thresholds associated with them are higher. Hence, from (26), it follows that only the very productive firms will be able to overcome the pro-competitive effects in larger markets and enjoy the benefits of selling to more consumers. Appendix A.3 characterizes the productivity thresholds for the latter firms.

\subsection{Relation to Existing Literature}

The utility function that I employ in the model described above represents a preference relation that is non-homothetic. ${ }^{9}$ In particular, it yields hierarchic demand due to bounded marginal

\footnotetext{
${ }^{9}$ Non-homothetic preferences have made a come-back in international trade (Markusen (2013) and Fieler (2011)).
} 
utility of consumption. ${ }^{10}$ Two additional functional forms that belong to the class of hierarchic demand systems have recently been introduced to the international trade literature featuring firm heterogeneity. First, Melitz and Ottaviano (2008) use linear demand for varieties to study how mark-ups respond to changes in market size and trade policy. Their framework features a numéraire good that is produced with identical linear technology across countries and is freely traded. These assumptions imply wage equalization across countries and thus income effects on prices are absent from their model. In Supplementary Appendix I, I drop the numéraire good and I characterize the general equilibrium of the model of Melitz and Ottaviano (2008) allowing for income effects. I then demonstrate that, in the augmented model, the price of a variety responds to changes in per-capita income and market size in the same qualitative fashion as in the model that I introduce in the present paper. However, upon inspecting the individual firm's pricing rule obtained from Melitz and Ottaviano's (2008) model, one can verify that the behavior of relative prices across countries can only be studied numerically. In addition, a testable prediction linking relative prices to measurable variables across countries cannot be derived since thresholds are not explicit functions of parameters and wages.

Second, Behrens et al. (2014) employ exponential (CARA) utility in a general equilibrium model of international trade with heterogeneous firms. They use the model to quantitatively assess the effects of the Canada-US trade liberalization on regional market aggregates such as wages, productivity, mark-ups, the mass of produced and consumed varieties, as well as welfare. While their model has desirable aggregate properties such as a gravity equation of trade under Pareto-distributed firm productivities, individual-firm prices and mark-ups are characterized via the Lambert-W function. Behrens et al. (2014) demonstrate that their model predicts a similar response of the price of a variety to changes in market characteristics as the framework that I develop. However, due to lack of tractability, relative prices across countries can only be examined numerically and a testable prediction that relates them to measurable variables is not available. In contrast, the non-homothetic preference representation that I employ offers tractability and it allows me to obtain a testable prediction that links relative prices to measurable variables, one of which is per-capita income.

In the model outlined in this paper, the price of a variety reflects the firm's marginal cost of production and delivery and the consumer's demand elasticity in a country, which can be seen from expression (21). Since the elasticity in expression (20) depends on the productivity threshold, it falls in the per-capita income and rises in the size of the destination. The effects are a byproduct

\footnotetext{
${ }^{10}$ This feature of the utility function gives consumption sets that are expanding in per-capita income. Sauré (2012) exploits this feature of the utility function in the homogeneous monopolistic-competition framework of Krugman (1980) and derives a positive relationship between per-capita income and the extensive margin of imports. The author's theoretical results are consistent with the empirical findings of Hummels and Klenow (2005) and Feenstra (2010). Relatedly, Bertoletti and Etro (2013) and Ushchev et al. (2014) provide characterization of monopolistic competition under more general preferences and discuss implications for trade flows and pricing. Finally, Young (1991) used the preference relation employed in the present paper in a Ricardian framework to analyze the growth patterns of countries when firms engage in learning-by-doing.
} 
of the assumed non-homothetic preference relation.

Before proceeding to the empirical section, it is important to note that alternative explanations of varying demand elasticities, and therefore varying prices, exist. Hummels and Lugovskyy (2009) use a Lancaster (1979) model to argue that richer agents consume more per good, which makes them more finicky and more willing to pay a high price in order to get closer to consuming their ideal variety. In their model, larger and richer (in per-capita terms) markets attract more firms and are consequently more competitive, which forces firms to charge lower prices there. Overall, the pro-competitive effect associated with higher per-capita income dominates the finickiness effect, so their model predicts that relative prices of identical varieties are lower in relatively richer (in per-capita terms) markets, after controlling for market population size differences. In contrast, the present model predicts that relative prices of identical varieties are relatively higher in richer markets, after controlling for market size differences. In the empirical section that follows, I find that relative prices are increasing in relative per-capita income levels, after controlling for market (population) sizes.

Another strand of literature that studies the interaction between varying demand elasticities and prices emphasizes the importance of search frictions. Lach (2007) hypothesizes that prices of consumption goods in Israel fell in the 1990s because there was a flow of immigrants with low search costs and high demand elasticities into the country during the period. Alessandria and Kaboski (2011) develop a formal search model where households send out shoppers to browse price quotes and to buy goods. Shopping takes time away from work. Having obtained price quotes, a shopper purchases one unit of the good if the lowest price quote is below some reservation level. Each household is indifferent between raising the reservation price and sending out additional shoppers, so the reservation price is higher in higher-wage countries. A large number of firms offer the same good to consumers in two different countries and take the price distribution as well as the reservation price of consumers as given. If the firm's price is lower than the reservation price, the firm sells to customers with one price quote. By increasing its price, the firm increases its revenue per sale but decreases the likelihood of a sale, since it increases the probability that customers with two price quotes have a second price quote that is lower than the firm's price. Any price on the support of the distribution results in identical firm profits, so firms choose to randomize. The mean transacted price is higher in the country with a higher wage because consumers search for price quotes less intensively there.

While the search framework can account for the observed price variation in household items, there is considerable room for a complementary explanation of the positive relationship between prices of tradables and per-capita income that builds on non-homothetic preferences. In the model of Alessandria and Kaboski (2011), consumers purchase the same set of goods independently of their income levels. Hence, the model yields no systematic relationship between the extensive margin of trade and per-capita income. In contrast, Jackson (1984), Hunter and Markusen (1988), Hunter (1991), Movshuk (2004), and Hummels and Klenow (2005) document a positive link be- 
tween the set of (imported and) consumed varieties and consumers' income. This positive link is a key prediction of the model that relies on non-homothetic preferences and it is at the heart of the mechanism that relates prices to per-capita income.

In sum, although existing models that generate varying demand elasticities can explain the positive relationship between prices of tradables and per-capita income, a mechanism that combines monopolistically-competitive firms and consumers with non-homothetic preferences does not only account for the observed price variation in the data, but is also consistent with broader empirical regularities in the international trade literature.

\section{Empirical Evidence of Price Discrimination}

In this section, I present a unique database that features prices of identical goods sold online, which allows me to establish a link between demand elasticities and mark-ups across countries. Guided by the model that I develop in previous sections, but also accounting for the particulars of the dataset, I estimate the elasticity of price with respect to per-capita income.

\subsection{Description of Data}

\subsubsection{Mango Price Data}

I collect prices from the online catalogues of a Spanish apparel manufacturer called Mango.

Why Mango? Three unique features of the data allow me to empirically test the price-discrimination hypothesis. First, products sold in each market are identical, so quality differences are not responsible for the variation in prices across markets. This feature of the data distinguishes the analysis from studies that employ unit values (see Hummels and Klenow (2005), Hummels and Lugovskyy (2009), Bastos and Silva (2010), Gorg et al. (2010), Alessandria and Kaboski (2011), Harrigan et al. (2011), Baldwin and Harrigan (2011), Johnson (2012), and Manova and Zhang (2012)). Second, the products employed in the analysis are sold exclusively online and they are not available in Mango's physical stores ensuring that the items' prices are not set to match the in-store prices, which may reflect local wages, rents, and distribution mark-ups, as in Hsieh and Klenow (2007), Alessandria and Kaboski (2011), Crucini et al. (2005a), Crucini et al. (2005b), Crucini and Shintani (2008), Crucini and Yilmazkuday (2014), Goldberg and Verboven (2001), Goldberg and Verboven (2005), Ghosh and Wolf (1994), and Haskel and Wolf (2001). Third, the items used in the study are produced in, stored in, and shipped from a single location to all destinations via DHL Express. These circumstances, together with information on Mango's shipping and handling policy and DHL's pricing policy, allow me to first construct measures of transaction prices for Mango items, and then disentangle destination-specific shipping costs from mark-ups. Below, I describe the company and the dataset in detail. 
Company Profile. "MANGO Fashion for the young, urban woman" is Mango's tagline. The company is a leader in fashionable, yet affordable, apparel and footwear products that target middle-income female consumers. In 2008, Mango established a men's line, H.E. by Mango; in 2011 the company launched an accessories line, Touch by Mango; and in 2013 it introduced Mango Kids and Mango Sports\&Intimates. Kordecka and Ricart (2009) describe Mango as being sandwiched between Zara (Inditex) - Spain's largest textile producer-and Sweden's H\&M on the bottom, and bridge fashion brands such as USA's Ralph Lauren Polo and Italy's Diesel on the top. While Mango's main competitors are often quoted to be Zara and H\&M, these firms offer cheaper products aimed for mass consumption (see Mango case studies by Pinilla (2007) and Kordecka and Ricart (2009)). The company opened its first store in Barcelona in 1984. As of 2013, Mango products were sold in 2598 physical locations (902 Mango stores and 1696 franchises) in 109 countries as well as via the company's website. ${ }^{11}$ Mango's financial statement dated December 31, 2012 shows that total annual sales amounted to 1.691 billion Euro, out of which 84 percent was generated from exports. Mango is the second largest textile exporter in Spain and employs 12,211 people.

Table 1: Mango's Sales Per Destination in Year 2010, 95 Countries

\begin{tabular}{l|ll} 
& Log Per-Capita GDP & Log Population \\
\hline $0.750^{* * *}$ & $0.457^{* * *}$ \\
$(0.083)$ & $(0.064)$
\end{tabular}

Regressand: Mango's sales per export destination, relative to sales in Spain, in logs. *** significance at $1 \%$-level, $R^{2}=0.546, \mathrm{~N}$. Obs 94, Standard errors in parentheses. Data Sources: Sales for manufacturer Mango from company's 2010 Sustainability Report. Nominal per-capita GDP and population for 2010 from WDI.

Mango is a highly-productive exporter when viewed through the lense of the model. First, Mango serves a very large number of markets. Second, Table 1 shows that Mango exports higher volumes to richer and bigger markets. These observations are in line with the model's predictions discussed in Section 3.3 above.

Admittedly, Mango is more complex than the typical firm described in the theory. For example, Mango does not produce items in house; instead it designs all products and sources the finished goods from suppliers based predominantly in China, Morocco, and Turkey (Exhibit 2 in Kordecka and Ricart (2009)). Yet, key elements of Mango's operations make the company well suited for an empirical examination of price discrimination. Based on interviews with Mango's management, Kordecka and Ricart (2009) document that Mango sources a given product from a particular supplier, regardless of the market to which the product is ultimately sold. Hence, marginal costs of production for a given good are identical across markets. ${ }^{12}$ In addition, all items

\footnotetext{
${ }^{11}$ Data on sales and employment for the fiscal year 2012 are from Mango's Annual Sustainability Report available at http://www.mango.com/web/oi/servicios/company/US/empresa/rsc/english_2012.pdf.

${ }^{12}$ To verify the information, I conducted a controlled experiment whereby I purchased an identical item from Mango's online store and had it directly dispatched to a customer in every destination analyzed in this paper.
} 
are stored in a single warehouse located in Palau de Plegamans, Spain, and dispatched via a third party to all destinations. Thus, prices of Mango items do not reflect destination-specific production and storage costs. Pinilla (2007) document, however, that prices of items sold in physical Mango outlets reflect the costs associated with: (i) delivering items from Spain to their final destination, and (ii) operating the local store (ex. rents and wages). For these reasons, I focus on Mango's online store, which I describe next.

Online Store. What makes Mango particularly well suited for a price discrimination study is the fact that, for a subset of countries, the company operates an online store at http://shop.mango.com. In my interview with Professor Joan Enric Ricart (IESE), the Mango case study author describes the online store as "just another Mango store" - the biggest one in fact. The online catalogue constitutes Mango's entire collection of the season, which features more than one thousand products offered in all the participating countries. Each item in the catalogue has a unique name and an 8-digit code reported in every country, which ensures accuracy and facilitates data collection.

Mango is a pioneer and a leader in online apparel retail as it launched its online store as early as year 2000. According to Kordecka and Ricart (2009), in 2007, the online store had a million visitors per month and accounted for a mere $0.4 \%$ of total sales, with Germany and the UK accounting for more that half of that statistic. By 2012, Mango's online sales accounted for $4 \%$ of total sales - a number that the company aimed to double in $2013 .{ }^{13}$ The statistic compares favorably to Zara's online sales, which accounted for $2.5 \%$ of the company's turnover in 2012, with H\&M lagging behind as it only serves a handful of markets online. ${ }^{14}$ Mango strives to create a virtual shopping experience that mimics customers' experience in their physical "boutiques" as much as possible. In addition, Mango is a very active participant in social media outlets and has launched a Mobile App. To summarize, in the (post-)financial crisis era of falling profit margins per physical store, the online store is Mango's growth engine in developed and emerging markets.

The online store, however, is dynamic in nature as the number of countries that it serves grows annually. In year 2012 - when this study was conducted-Mango's online store served 39 distinct countries: 2 in North America, 7 in Asia, and the remainder in Europe. A subset of 29 countries shared two key characteristics that deem them suitable for the empirical study of price discrimination.

1. Online-Only Catalogue. As mentioned above, the online store offers the entire Mango collection of the season, a portion of which is also sold in the company's physical stores. Should the company be matching the prices of the items via the two outlets, the items' online prices would reflect local non-tradable contributions per Mango's pricing policy described above. For this reason,

Pictures of product labels are available upon request.

${ }^{13}$ Source: www.e-commercefacts.com press release dated April 17, 2013.

${ }^{14}$ Source: www.businessoffashion.com press release dated March 7, 2013. 
I restrict the empirical analysis to only those items that are sold exclusively online. The onlineonly products include apparel, footwear, and accessories, much like the in-store products, and the price range of the items in the two outlets is similar. ${ }^{15}$ According to Kordecka and Ricart (2009), physical Mango stores are boutiques rather than warehouses - they carry a limited selection of the collection that customers can try on and buy. In order to maintain the appearance of a boutique and to minimize storage costs, Mango offers a large fraction of its collection exclusively online.

I consider products from the Summer 2012 catalogue, which became available online in April of 2012. ${ }^{16}$ In this catalogue, there are 245 items in total sold exclusively online to 29 markets in Europe, North America, and Asia. These items are easily identifiable on the website as they are given an explicit label: "exclusively online". In addition, one can manually verify that the items are not available in any physical store in the 29 markets using Mango's "Search In Store" button. ${ }^{17}$

2. Uniform Shipping \& Handling Policy. The online store segments national markets. Each participating country has a website and customers from one country cannot buy products from another country's website due to shipping restrictions. Thus, a customer with a shipping address in Germany can only have items delivered to her if purchased from the German Mango website. As described earlier, Mango's products are stored and dispatched from a single warehouse in Palau de Plegamans, Spain, to all destinations. Crucially, online-only items are neither shipped to a physical store first, nor is their price chosen to match the price in a physical outlet. For the 29 markets included in this study, upon receiving an online order, Mango ships items via DHL Express. ${ }^{18}$

\footnotetext{
${ }^{15}$ One concern is that the price of online-and-in-store products affects the price of online-only items, in which case local costs that shape in-store product prices may be reflected also in online-only prices. Examining online-only products minimizes potential biases due to local costs as much as possible; however, the possibility of a bias cannot be excluded. The direction of the bias, however, is unclear. In order to generate an interaction between the prices of goods produced by a multi-product firm, one must depart from a monopolistically-competitive environment in favor of a model where multi-product firms compete à la Bertrand or Cournot (see Eckel and Neary (2009) and Feenstra and Ma (2007)). In such environments, an increase in the cost and hence price of one good (ex. in-store good due to a rise in a non-tradable cost component) results in a fall/rise in the price of the other good sold by the same firm in the same market (ex. online-only good) if the other good is a substitute/complement. This suggests that, in richer countries, characterized by higher local costs, Mango would price online-only goods at a lower/higher price than online-and-in-store goods if the former are substitutes/complements; hence, the elasticity of price with respect to income obtained from online-only data would be underestimated for some products and overestimated for others. I leave it to future research to explore this theoretical result in a multi-country setting where markets are characterized by different per-capita income levels and local costs. Bekkers and Simonovska (2015) take a first step in this direction and study the behavior of single-product firms with market power.

${ }^{16}$ Summer and Winter 2008 catalogue data yield similar results, which are available upon request. While the multiple-season data minimizes the possibility of seasonal bias, the number of goods and countries in the 2008 sample is smaller. Moreover, in 2008, Mango's website did not distinguish between items that were available exclusively online versus in physical stores as well. The distinction is very important in order to minimize any biases that arise due to non-tradable price components.

${ }^{17}$ As of 2014, it appears that Mango is no longer labeling items as "exclusively online", although manual verification is still available. Clearly, this would make new data collection efforts much more difficult. To my knowledge, unlike its competitors who are listed above, Mango is the only retailer for which one can verify the fact that items are sold exclusively online and that they are produced, stored, and shipped from a single location to all the destinations.

${ }^{18}$ I conducted a controlled experiment and collected DHL tracking codes for an identical item sent to all destinations and verified that the shipping and production origin are identical, regardless of destination.
} 
Table 2: Mango's Shipping \& Handling Fees in Euro, 29 Countries

\begin{tabular}{l|rrl|l|rrr}
\multicolumn{3}{c}{ Fee if buy } & \multicolumn{3}{c}{ Fee if buy } \\
Destination & Min Buy & \multicolumn{1}{c}{$<$ Min } & $>$ Min & Destination & Min Buy & $<$ Min & $>$ Min \\
\hline Austria & 30.00 & 2.95 & 0.00 & Lithuania & 150.31 & 11.29 & 5.50 \\
Belgium & 30.00 & 2.95 & 0.00 & Luxembourg & 30.00 & 2.95 & 2.95 \\
Bulgaria & 250.54 & 12.78 & 0.00 & Macao & 146.82 & 9.79 & 0.00 \\
Canada & 114.78 & 7.65 & 0.00 & Malta & 150.00 & 11.95 & 3.95 \\
Cyprus & 150.00 & 11.95 & 3.95 & Netherlands & 30.00 & 2.95 & 0.00 \\
Czech Rep. & 265.99 & 12.05 & 0.00 & Norway & 165.00 & 13.08 & 3.83 \\
Denmark & 75.14 & 7.93 & 0.00 & Poland & 59.59 & 9.33 & 2.15 \\
Estonia & 150.00 & 11.95 & 3.95 & Romania & 150.00 & 11.95 & 0.00 \\
Finland & 75.00 & 7.95 & 0.00 & Slovakia & 150.00 & 11.95 & 3.95 \\
Germany & 30.00 & 2.95 & 0.00 & Slovenia & 150.00 & 11.95 & 3.95 \\
Greece & 75.00 & 7.95 & 0.00 & Sweden & 89.11 & 10.04 & 0.00 \\
Hong Kong & 146.82 & 9.79 & 0.00 & Switzerland & 187.89 & 14.89 & 0.00 \\
Hungary & 135.66 & 11.18 & 0.00 & UK & 36.50 & 3.59 & 0.00 \\
Ireland & 75.00 & 7.95 & 0.00 & Spain & 30.00 & 2.95 & 0.00 \\
Japan & 177.48 & 14.86 & 0.00 & & & & \\
\hline
\end{tabular}

Data Sources: Fees in Summer 2012 from shop.mango.com. Exchange rate for April 2012 from ECB.

Mango's shipping and handling policy is as follows: (i) if a purchase is below a minimum value, then the customer pays an explicit flat shipping fee; (ii) if a purchase is above a minimum value, then the customer pays a lower explicit flat fee (often zero). Both the fees and the minimum value vary by country and are summarized in Table 2. ${ }^{19}$ Supplementary Appendix VI contains further details regarding Mango's shipping and handling charges and provides insights into the magnitudes of these charges compared to items' prices.

The shipping and handling policy of Mango is symptomatic of a quantity-discount pricing rule typically employed by online retailers who face heterogeneous consumers within and across markets. ${ }^{20}$ The results from the empirical analysis that follows suggest that Mango's shipping and handling charges primarily reflect the company's shipping costs to, and back from, each market. The latter relates to Mango's return policy. Table 3 documents Mango's return and exchange policy for the 29 markets studied in this paper. ${ }^{21}$ The second (fifth) column states whether an item can

\footnotetext{
${ }^{19}$ Note that: (i) Mango's shipping and handling fees apply to all items purchased online: both online-only items and items that are available online and in stores; (ii) As of May 2014, Mango has eliminated the positive charge for purchases above threshold and has reduced the shipping charges for purchases below the threshold.

${ }^{20}$ To illustrate the pricing rule, consider the simplest two-consumer-type scenario. A firm faces low- and highvaluation consumers in a given market, where valuation is positively linked to consumer income in preference specifications that feature income effects (see Chapter 3 in Tirole (1988)). In order to serve both consumer types (within a country), the firm offers the following price menu: a low per-unit price for purchases above a cutoff (the quantity discount) and a high per-unit price otherwise. The number of combinations of cutoffs and per-unit prices increase with the number of consumer types in a market. Across segmented markets (for example countries), the firm price discriminates as predicted by the model developed in the present paper. In particular, the firm enjoys higher mark-ups in markets with higher per-consumer income due to the higher average valuation of the good there.

${ }^{21}$ Note that, like Mango's shipping and handling fees, the return and exchange policy applies to all items purchased
} 
be returned in a physical store, while the third (sixth) column states whether the shipping address for returns by mail is in the destination country (local) or in Spain. Destinations differ along both dimensions. Mango allows customers to return items in physical stores in some countries and not in others. In addition, there are countries in which Mango allows size exchanges only, which obviously does not apply to the online-only items analyzed in this paper as physical stores do not carry them. Hence, these destinations can be grouped with the ones in which no in-store returns and exchanges are allowed for the purpose of the study. Finally, in certain countries, returns can only be processed in a single physical store but not in other stores. Differences arise with respect to returns via mail as well. Customers in one group of countries must mail returns to Spain, while customers in another group must mail returns to a local address. A third set of customers can only return items via mail by scheduling a home pick-up by a delivery service.

Table 3: Mango's Return \& Exchange Policy, 29 Countries

\begin{tabular}{l|ll|l|ll}
\multicolumn{2}{c}{ Return/Exchange } & \multicolumn{2}{c}{ Return/Exchange } \\
Destination & In Store & Via Mail & Destination & In Store & Via Mail \\
\hline Austria & Yes & Local & Lithuania & Only Size Change & Spain \\
Belgium & Yes & Local & Luxembourg & Yes & Spain \\
Bulgaria & No & Spain & Macao & Yes & Local \\
Canada & Yes & Home Pick-Up & Malta & Yes & Spain \\
Cyprus & Yes & Spain & Netherlands & Yes & Local \\
Czech Rep. & Yes & Spain & Norway & Yes & Home Pick-Up \\
Denmark & Yes & Local & Poland & Yes & Local \\
Estonia & Only Size Change & Spain & Romania & No & Spain \\
Finland & Yes & Spain & Slovakia & No & Spain \\
Germany & Yes & Home Pick-Up & Slovenia & No & Spain \\
Greece & No & Spain & Sweden & Yes & Spain \\
Hong Kong & Yes & Local & Switzerland & Yes & Home Pick-Up \\
Hungary & No & Local & UK & Yes & Local \\
Ireland & Only 1 Store & Local & Spain & Yes & Spain \\
Japan & Only 1 Store & Local & & & \\
\hline
\end{tabular}

Data Source: Policy in Winter 2014 from shop.mango.com.

According to Ricart, the reasons behind the country-specific return and exchange policy range from logistical capabilities to government regulations. In addition, it is very likely that the return and exchange policy will change as Mango's e-commerce evolves. For the study of price discrimination, the key concern is that Mango's costs to process returns, adjusted by the probability of a return, may be country-specific and may be reflected in the item's price. For this reason, I control for Mango's return policy in the empirical analysis which follows.

With the shipping and handling policy in mind, the challenge that remains is to construct per-unit (or transaction) prices for each country accounting for the existence of different types of online: both online-only items and items that are available online and in stores. 
consumers within each country. ${ }^{22}$ I consider three cases. In the first, and benchmark, specification, I construct per-good prices inclusive of shipping costs, assuming that each agent in every destination purchases a single item only. If the price for item $m$ in destination $j$ is (i) below the minimum-purchase requirement as listed in Table 2, I add the flat shipping fee listed in the third (seventh) column to the item's price; (ii) above the minimum-purchase requirement, I add the flat shipping fee listed in the fourth (eighth) column to the item's price. In the second specification, found in Section 4.2.3, I instead assume that consumers are "shipping-cost minimizers" — they purchase just enough so as to satisfy the minimum threshold listed in Table 2. In this case, I spread the flat shipping fee for purchases above the threshold over the bundle of goods - namely, I scale the prices of goods by the ad valorem shipping fee. ${ }^{23}$ In the third case, contained in Supplementary Appendix V, I verify that the estimates of the elasticity of price with respect to per-capita income are robust when analyzing items' prices as listed on Mango's website - namely, prices that do not explicitly account for the shipping and handling charges.

Additional Considerations. Above I describe the two main criteria for featuring 29 markets in the study. In this section, I discuss the remaining 10 countries that were excluded from the study. The USA, China (mainland), India, Malaysia, Philippines, Turkey, and Russia were excluded because of different shipping and handling policies. As Kordecka and Ricart (2009) and Pinilla (2007) document, Mango rents a warehouse in New Jersey which distributes items within the USA. The online store, however, serves Canadian consumers directly from Spain, which is not coincidental. Pinilla (2007) documents that Mango entered Canada prior to entering the USA for two reasons: (i) Mango's management perceives the Canadian market as more similar to the European markets rather than to the US market ${ }^{24}$; (ii) US import quotas on textiles from China complicated the production process, as Mango had to look for suitable suppliers who also had a quota for bringing garments into the USA. With these considerations in mind, Mango's entry strategy to the USA was delayed and different in nature compared to the Canadian and European markets. In fact, Mango entered the US market neither via a franchise nor by opening its own store. Instead, Mango penetrated the US market by partnering up with JC Penny and opening stands inside their stores. ${ }^{25}$

Similarly, India, Malaysia, and the Philippines are excluded from the study because these markets are served from Mango's distribution center in Singapore, while China is served from a

\footnotetext{
${ }^{22}$ Due to the lack of a time-series dimension to the dataset, one type of consumer that I do not obtain insights on is the "sale shopper". Chevalier and Kashyap (2011) document that, due to the existence of such consumers, the average transacted price over time is a weighted average of a listed price and a sales price. With their findings in mind, an important extension of the present study would be to examine Mango's dynamic pricing over time and across countries.

${ }^{23}$ For example, in Cyprus, I multiply each item's price by the fraction 3.95/150.

${ }^{24}$ In line with this, in the first round of study that I conducted using 2008 data, the US online store featured an entirely different collection from the European and Canadian counterparts.

${ }^{25}$ Source: http://online.wsj.com article dated August 11, 2010.
} 
local warehouse (see Pinilla (2007)). At the time that I conducted the study, I verified that Hong Kong, Macao, and Japan were served directly from Spain, which is not coincidental. Pinilla (2007) documents that Mango's management views Euro, Yen, and Dollar (broadly defined) zones as "safe" and the company has traditionally entered these markets predominantly via wholly-owned shops as opposed to franchises. Similarly, Mango has a common policy across these markets with respect to the online store.

Russia was also excluded due to differences in shipping and handling policies. A local carrier, rather than DHL, operates in Russia and the origin of the shipment could not be verified after repeated attempts. In addition, Pinilla (2007) quotes Mango's management that “... it is very complicated to manage in countries like Russia, where an informal economy abounds. Given the specific peculiarities of this country, in this case, it is better for a local businessman to do it as he knows what is going on.... A local businessman is used to working in an unstable environment, while the company is not used to working in this type of environment. It is easier for the local businessman to work in this way."

Finally, I exclude France, Italy, and Portugal from the study because the online exclusive collection was not offered there as such. ${ }^{26}$ In fact, I manually verified that all of the online-only items are sold in these markets, however, they are not sold exclusively online and are not labelled as such. I verified that the items are available in physical stores in these markets via the "Search In Store" button. What makes these markets different? In 2010, these three markets constituted $15 \%$ of Mango's total sales, and Pinilla (2007) notes that Mango operates so-called flagship stores in these countries. ${ }^{27}$ Flagship stores carry the entire collection, are very large and centrally located, and are the "face of the company." So, it is likely that these stores hold a large enough stock of items to be able to satisfy the (local) demand from online customers as well. In sum, these markets were dropped from the analysis since Mango appears to be solving a different problem there compared to the remaining 29 countries. $^{28}$

Admittedly, having excluded certain countries from the study, the sample size is not very large. Nonetheless, the 29 markets that I use in this study account for almost $50 \%$ of Mango's sales in 2010. Hence, these countries are highly representative of Mango's operations, which makes them interesting to study. A study that is tailored to the special-case countries discussed above would

\footnotetext{
${ }^{26}$ These markets were included in the previous study that featured Summer and Winter 2008 catalogue data and yielded similar results, which are available upon request. See footnote 16 above for details.

${ }^{27}$ Mango also operates such stores in the home market, Spain, where the items were also not labelled as onlineonly. However, all prices in the empirical exercises that follow are computed relative to prices in Spain and all regressions include a constant term. Thus, even if Spanish prices reflect a non-traded component, the effect is captured by the constant term.

${ }^{28}$ As a multi-product firm, Mango jointly chooses the product mix and the per-product price for each market. If the product mix is country-specific and prices feature cannibalization effects, as in the models by Eckel and Neary (2009) and Feenstra and Ma (2007), then there would be systematic differences in prices across countries and products - a feature that is absent from the model that I develop. Since product-country-specific fixed effects cannot be identified in the empirical analysis due to the nature of the dataset ( $M$ products in $N$ countries in a given year), I only consider the 29 markets in which Mango's optimal product mix is identical.
} 
be less general and less informative of the pricing practices of typical online retailers.

\subsubsection{Additional Data}

As noted above, Mango's shipping and handling provider in the 29 markets I study is DHL. While, information on the actual cost of shipping and handling that Mango incurs is not publicly available, I can proxy the costs by using reported DHL prices. I collect price quotes for one-time identical shipments to all the destinations in the sample from the Spanish DHL website. I verify that DHL offers percentage discounts to the quoted prices to corporations that carry out multiple shipments. Crucially, these discounts are not destination-specific, so they do not affect the relative price that a client pays to ship to different destinations. For example, a client who ships $\$ 1500$ worth of merchandise per month receives a $32 \%$ discount on all shipments regardless of the destination. ${ }^{29}$ I use logged DHL shipping prices, normalized by the price to ship within Spain, to approximate Mango's cost to ship to its export markets, relative to the domestic costs of transport. In Section 4.2.3, I demonstrate that the results are robust to controlling for standard gravity variables.

Prices on Mango's website are recorded in destination currency. One half of the countries in the sample were members of the Euro area in 2012. For the remaining countries, I convert prices into Euro using the European Central Bank's average exchange rate for April of 2012 - the month when the catalogue was posted online and the data were collected. ${ }^{30}$ I further control for Eurozone membership in order to capture the effect that currency areas have on price variations.

The items' prices reported on Mango's website are inclusive of value added taxes (VAT) in the countries that are members of the European Union and the European Free Trade Association, and sales taxes and import tariffs in the remaining countries. Therefore, it is important to control for policy instruments in the pricing analysis. I obtain data on VAT rates on apparel for 2012 from the European Commission. In addition, I collect data on sales taxes on clothing for the remaining countries from their respective statistical agencies. ${ }^{31}$ Finally, I use tariff data on clothing from the World Integrated Trade Solution (WITS) database.

The intensity of competition from rivals surely shapes Mango's mark-ups in each market.

\footnotetext{
${ }^{29}$ Information on DHL prices and policies is available at http://www.dhl.es/en.html. Evidence from personal correspondence with a DHL representative is available from the author upon request.

${ }^{30}$ I obtain nearly identical quantitative results using exchange rates for February and March of 2012, which capture the fact that Mango may have priced its products one or two months prior to posting the catalogue online. These results are available upon request. Note that it is redundant to repeat the analysis using exchange rates that were effective three or more months prior to the month when the catalogue was posted online since seasonal catalogues have a lifespan of three months. Given the short product lifespan, exchange rate volatility is likely not a major concern for Mango. Hence, the data are useful for a cross-sectional study such as the one undertaken in this paper. In that respect, the exercise in this paper is very different from, and complementary to, typical empirical pricingto-market investigations, which rely on time variation in prices of products with similar characteristics in order to infer the degree of nominal exchange-rate pass through (see Goldberg and Knetter (1997) for a comprehensive review of the relevant literature and Fitzgerald and Haller (2014) for a recent pricing-to-market study using very detailed plant level data for the UK and Ireland).

${ }^{31}$ For Canada, I compute a population-weighted average tax rate across all of its provinces. In Hong Kong and Macao, the apparel and footwear sales tax and tariff is zero.
} 
In fact, measuring Mango's competition in each destination is the most difficult task. Guided by the model, I begin by approximating market presence by the expenditure share on Spanish apparel and footwear products in each market, $\lambda_{i j}$. I construct two measures of this variable. In the benchmark specification, I let the numerator in (23) be country j's imports from Spain in commodity codes H0- 61, 62, and 64 in the Comtrade data in year 2010, denominated in current USD. I let the denominator be the expenditure on apparel and footwear products in each country in 2010, denominated in current US dollars. To construct expenditure, I multiply GDP (in current US dollars) by the expenditure share of GDP on basic headings in apparel and footwear from the 2005 ICP database. The three categories corresponding to apparel and footwear are: 1103111 Clothing materials and accessories, 1103121 Garments, and 1103211 Footwear. $^{32}$

For robustness, I also present results that use an alternative measure of $\lambda_{i j}$-the trade share. In that case, the numerator is country j's imports from Spain in commodity codes H0- 61, 62, and 64 and the denominator is Gross Output for the same industries, in year 2008, denominated in current USD. I pool gross output data for the apparel and footwear industry from a variety of sources including Stats.OECD, Prodcom, as well as individual countries' statistical agencies. ${ }^{33}$ A natural concern is that the trade shares are measured with error as the gross output data are pooled from a variety of sources, which is why this specification is not my benchmark. A more serious concern is that the trade share in apparel and footwear may not be the most relevant measure of destination-specific competition for Mango. For example, Melitz and Ottaviano (2008) argue that mark-ups vary negatively with market size, measured by the population size of the country. Prices are also decreasing in market size in the Hummels and Lugovskyy (2009) model. In fact, Proposition 2 establishes that the model developed in the present paper also predicts that relative prices are decreasing in relative market sizes, under reasonable parameter restrictions. Hence, I consider a third measure of competition-destinations' population size for the year 2010 obtained from the World Development Indicators (WDI).

Finally, in the benchmark analysis, I use per-capita GDP (in current US dollars) for the year 2010 from the WDI. In Supplementary Appendix III, I repeat the empirical analysis using five different measures of per-capita income or expenditure: per-capita nominal consumption, nominal household consumption, and PPP-adjusted GDP for 2010, and per-capita nominal GNI and nominal GNI measured according to the Atlas method for 2009, all from WDI.

\subsubsection{Summary}

I conclude the description with a summary of the price data. Table 4 reports the mean product price across all 245 items, denominated in Euro and computed relative to Spain, in each of the twenty-eight export markets used in the analysis. For each country, there are three price statistics corresponding to the three assumptions about consumers laid out above: (i) single-item purchaser,

\footnotetext{
${ }^{32}$ This is the most recent detailed ICP expenditure data available.

${ }^{33} 2008$ is the most recent year for which data are available for all the countries in the sample.
} 
(ii) shipping-cost minimizer, and (iii) web-listed price. The transacted price differs considerably between the single-item purchaser and the shipping-cost minimizer, who pays very similar prices to the web-listed ones since shipping costs are very low (zero for two-thirds of the countries) once spread over the entire bundle (see Supplementary Appendix VI). Foreign consumers who purchase one item pay on average $58 \%$ more than Spanish ones, with Japanese customers paying as much as 2.2 times more and Dutch ones paying only 10\% more than Spanish ones do. In contrast, foreign consumers who purchase enough items so as to minimize the shipping fee pay on average $34 \%$ more than Spanish ones, with Japanese customers paying $73 \%$ more and Romanian ones paying only $3 \%$ more than Spanish ones do. Since prices are inclusive of (international) shipping fees, trade barriers partly account for the price wedge between the domestic country and the export markets.

Table 4: Per-Capita Income and (Geometric) Average Item Price, Relative to Spain, 29 Countries

\begin{tabular}{l|llllll}
\hline Country & Austria & Belgium & Bulgaria & Canada & Cyprus & Czech Rep. \\
One purchase & 1.189 & 1.204 & 1.693 & 1.772 & 1.568 & 1.543 \\
Ship minimize & 1.224 & 1.243 & 1.250 & 1.625 & 1.185 & 1.121 \\
Web listed & 1.224 & 1.243 & 1.250 & 1.625 & 1.154 & 1.121 \\
\hline Country & Denmark & Estonia & Finland & Germany & Greece & Hong Kong \\
One purchase & 1.735 & 1.702 & 1.440 & 1.189 & 1.419 & 1.855 \\
Ship minimize & 1.582 & 1.339 & 1.228 & 1.224 & 1.201 & 1.599 \\
Web listed & 1.582 & 1.305 & 1.228 & 1.224 & 1.201 & 1.599 \\
\hline Country & Hungary & Ireland & Japan & Lithuania & Luxembourg Macao \\
One purchase & 1.634 & 1.555 & 2.204 & 1.652 & 1.417 & 1.855 \\
Ship minimize & 1.276 & 1.363 & 1.729 & 1.328 & 1.615 & 1.599 \\
Web listed & 1.276 & 1.363 & 1.729 & 1.281 & 1.471 & 1.599 \\
\hline Country & Malta & Netherlands & Norway & Poland & Romania & Slovakia \\
One purchase & 1.684 & 1.105 & 1.897 & 1.382 & 1.457 & 1.575 \\
Ship minimize & 1.322 & 1.123 & 1.503 & 1.127 & 1.0273 & 1.196 \\
Web listed & 1.288 & 1.123 & 1.469 & 1.088 & 1.0273 & 1.165 \\
\hline Country & Slovenia & Sweden & Switzerland & UK & Spain & Mean (St.Dev.) \\
One purchase & 1.819 & 1.622 & 2.094 & 1.483 & 1.0000 & 1.577 (0.281) \\
Ship minimize & 1.485 & 1.324 & 1.604 & 1.536 & 1.0000 & 1.344 (0.201) \\
Web listed & 1.446 & 1.324 & 1.604 & 1.536 & 1.0000 & 1.329 (0.198) \\
\hline
\end{tabular}

One purchase: $\quad \log \bar{p}_{\text {exp }}=0.456^{* * *}+0.005 \quad \log y, \quad R^{2}=0.000, \quad$ N. Obs. 28

Ship minimize: $\quad \log \bar{p}_{\text {exp }}=0.298^{* * *}+0.112^{* * *} \log y, \quad R^{2}=0.319, \quad$ N. Obs. 28

Web listed: $\quad \log \bar{p}_{\text {exp }}=0.287^{* * *}+0.110^{* * *} \log y, \quad R^{2}=0.313, \quad$ N. Obs. 28

$* * *$ significance at $1 \%$-level

The importance of shipping costs in driving price differences across countries is more apparent in Figure 1, which plots the mean of logged prices, relative to Spain, across all products in each export market, against the logged relative per-capita income levels. A simple linear regression of the mean logged price on logged per-capita income suggests that doubling a destination's per-capita GDP raises prices paid by cost-minimizers (as well as web-listed prices) by $11 \%$. In contrast, richer 

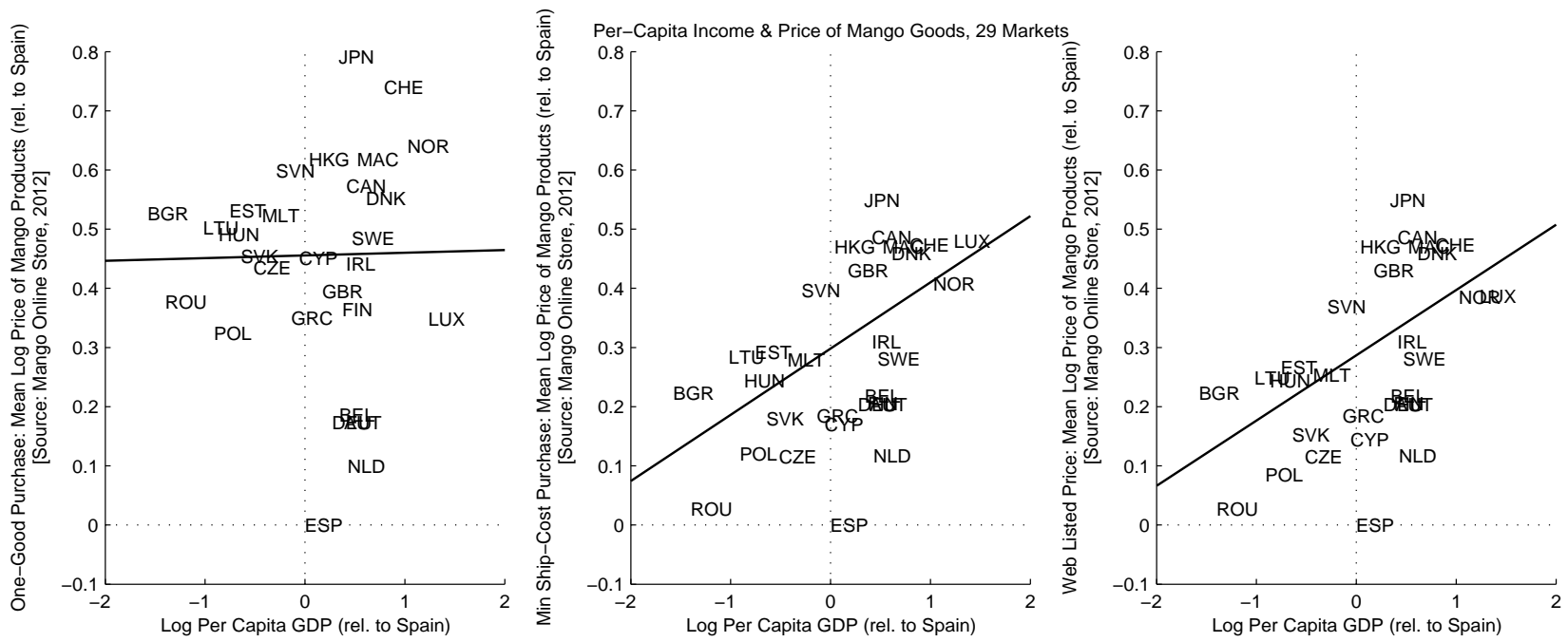

Figure 1: Per-Capita Income and Geometric Mean Price of Identical Mango Products

single-item purchasers do not appear to pay a higher price than poorer ones do. As I demonstrate in the next section, this apparent disconnect between prices and per-capita income is due to the fact that shipping costs, which constitute a large portion of a single item's price, are systematically lower for richer destinations. Once I control for shipping costs, the positive link between the transacted price and per-capita income emerges.

\subsection{Empirical Analysis}

\subsubsection{Econometric Model}

I use the theoretical model's testable prediction in expression (24) as a starting point toward the econometric specification. With the specific characteristics of Mango in mind, I use Spain as numéraire, drop country-of-origin subscripts, and discretize the set of varieties to arrive at the following econometric model

$$
\log \left(\frac{p_{j m}}{p_{s m}}\right)=\beta_{y} \log \left(\frac{y_{j}}{y_{s}}\right)+\beta_{d h l} \log \left(\frac{d h l_{j}}{d h l_{s}}\right)+\beta_{\lambda} \log \left(\frac{\lambda_{j}}{\lambda_{s}}\right)+\beta_{\kappa} \log \left(\frac{\kappa_{j}}{\kappa_{s}}\right)+\beta_{g} \log \left(\frac{g_{j}}{g_{s}}\right)+\psi_{j m} .
$$

$p_{j m} / p_{s m}$ is the Euro-denominated price of item $m$ in country $j$, relative to Spain - $s . y_{j}$ is destination $j$ 's per-capita income. Based on the theoretical model's testable prediction in expression (24), one can hypothesize that $\beta_{y}=1 /(2(\theta+1))>0 . d h l_{j}$ is DHL's destination-specific shipping price, which proxies the trade cost in the benchmark specification, so from the model's testable prediction in expression (24), it is expected that $\beta_{d h l}>0$. In the robustness analysis, I add standard gravity variables (which I describe in Section 4.2.3) to further control for the effect of trade barriers on prices. $\lambda_{j}$ is Mango's market share in destination $j$, which reflects the competition the firm faces there. It is measured by: (i) country $j$ 's import share of apparel and footwear from Spain 
constructed from Comtrade and ICP expenditure data; (ii) the same statistic constructed from Comtrade and Gross Output data; or (iii) country j's population size. In cases (i) and (ii), based on the model's testable prediction in expression (24), one can hypothesize that $\beta_{\lambda}=1 /(2(\theta+1))>0$. In case (iii), based on the theoretical result in Proposition 2 , it is expected that $\beta_{\lambda}<0$.

In addition, I control for destination-specific apparel and footwear sales taxes and tariffs on Spanish imports. I denote the gross sales tax and tariff in country $j$ by $\kappa_{j}$. In Supplementary Appendix II, I add to the theoretical model from Section 2 per-unit taxes and tariffs, and I derive a testable prediction. The augmented model yields identical coefficients on per-capita income, trade barriers, and market shares as the benchmark model, and a positive coefficient on gross taxes and tariffs, $\beta_{\kappa}=(2 \theta+1) /(2(\theta+1))>0$.

$g_{j}$ is the Gini coefficient of income inequality in country $j$ collected from the CIA World Factbook. This control is motivated by the fact that Mango's quantity-discount pricing strategy described in Section 4.1.1 is optimal in environments in which firms serve consumers with various income levels within a country. While I do not explicitly derive the optimal pricing rule in an economy that features consumers with heterogeneous incomes within a country, I refer the reader to such extensions of this model considered by Bekkers et al. (2012) and Pieters (2014). The theoretical findings can be summarized as follows: keeping per-capita income fixed, (i) firms find it optimal to charge lower prices in countries with higher income inequality if they choose to sell positive amounts to both rich and poor consumers; and (ii) firms charge higher prices in countries with higher income inequality if they only serve high-income consumers. The former appears to be the case for Mango, otherwise the firm would not be pursuing the quantity-discount strategy described above. Hence, it is expected that $\beta_{g}<0$, which has been documented empirically by Bekkers et al. (2012) and Pieters (2014).

In addition to the regressors explicitly listed, I include five indicator variables. The first is a Euro-currency indicator and its coefficient is expected to be negative as currency-union membership effectively reduces trade barriers (see Rose (1999)). ${ }^{34}$ The remaining four indicators describe Mango's return policy. The first takes the value of one if in-store returns are allowed, the second if returns are allowed in only one store, the third if returns via mail are sent to a local address (in the consumer's country of residence), and the fourth if returns via mail are picked up from the customer's home. As discussed in Section 4.1.1, many factors shape Mango's return policy, so it is not straightforward to sign the coefficients on these indicators. It is, however, expected that, if Mango incurs lower costs to process returns (in store or via mail) locally, and if these costs are passed onto consumers, then lower-cost options should translate into lower prices of items.

Since the econometric model is tailored to best capture specific characteristics of Mango and consequently includes additional variables that are outside of the theoretical model, the estimation

\footnotetext{
${ }^{34}$ The indicator takes on the value of 1 if the country's Mango website lists prices denominated in Euro and zero otherwise. Naturally, all Eurozone countries satisfy this category. Interestingly, Mango also prices its items in Euro in Romania - a non-Eurozone country.
} 
is not meant to structurally distinguish the model that I develop in this paper from other existing formulations. Instead, the model can be used as a guide to interpret the signs of the coefficient estimates. Finally, it remains to note that $\psi_{j m}$ is an error term and that all regressions include product fixed effects as well as a constant.

\subsubsection{Benchmark Results: One-Item Purchases}

Table 5: Benchmark Results-One-Item Purchase, 29 Countries

Market Share Measure

\begin{tabular}{l|lll} 
& trade shr $(\mathrm{ICP})$ & trade shr $(\mathrm{GO})$ & population \\
\hline pc.gdp & $0.160^{* * *}$ & $0.143^{* * *}$ & $0.116^{* * *}$ \\
dhl & $(0.049)$ & $(0.047)$ & $(0.044)$ \\
& $0.369^{* * *}$ & $0.370^{* * *}$ & $0.284^{* * *}$ \\
market.shr & $(0.096)$ & $(0.091)$ & $(0.080)$ \\
& 0.018 & 0.010 & $-0.021^{*}$ \\
tax/tariff & $(0.013)$ & $(0.009)$ & $(0.012)$ \\
gini & 0.106 & -0.089 & -0.108 \\
& $(0.564)$ & $(0.535)$ & $(0.522)$ \\
euro & -0.031 & -0.063 & -0.052 \\
in.all.stores & $(0.114)$ & $(0.116)$ & $(0.109)$ \\
& $-0.170^{* * *}$ & $-0.166^{* * *}$ & $-0.182^{* * *}$ \\
in.one.store & $(0.037)$ & $(0.037)$ & $(0.038)$ \\
& $-0.125^{* * *}$ & $-0.139^{* * *}$ & $-0.126^{* * *}$ \\
mail.local & $(0.046)$ & $(0.048)$ & $(0.043)$ \\
& 0.065 & 0.039 & 0.095 \\
home.pick.up & $(0.069)$ & $(0.070)$ & $(0.067)$ \\
& $-0.098^{* * *}$ & $-0.088^{* *}$ & $-0.078^{* * *}$ \\
& $(0.034)$ & $(0.035)$ & $(0.033)$ \\
within $R^{2}$ & 0.041 & 0.046 & 0.064 \\
\hline & $(0.055)$ & $(0.055)$ & $(0.054)$ \\
\hline
\end{tabular}

The regressand is the price of an item sold by Mango in one of 28 destinations, measured relative to the price of the same item sold in Spain, in logs. Regressors and expected signs of coefficients are described in Section 4.2.1. $*, * *, * * *$ indicates significance at $10 \%, 5 \%$-level, $1 \%$-level, respectively.

Standard errors clustered by country in parentheses.

Observations: 6860. Fixed Effects: 244 (relative to good 1).

I estimate the coefficients in the econometric model above using the OLS estimator and I cluster all errors by destination. The empirical results are reported in Table 5. Across the three specifications that differ in the measure of market share, the coefficient estimate on per-capita income varies between 0.12 and 0.16 and is highly statistically significant. Hence, doubling the per-capita income of a country is associated with at least a $12 \%$ increase in the price of identical 
goods sold by Mango there. The coefficient estimates of the DHL shipping costs range between 0.28 and 0.37 and are highly statistically significant. In fact they are at least twice the magnitude of the coefficient estimates on per-capita income. The finding is driven by the fact that Mango uses DHL Express to ship items, and the shipping charges for single-item purchases constitute $35 \%$ of the typical item's web-listed price (see Supplementary Appendix VI).

The coefficient on trade shares is not statistically different from zero, whether measured using ICP expenditures or gross output on apparel and footwear in the denominator. Measurement error, which biases coefficient estimates toward zero, is a likely explanation for this finding. ICP expenditure shares for year 2005 are the most recent available observations and are used to construct expenditures on apparel and footwear in 2010 in the first measure of trade shares. In the second measure, to maximize country coverage: first, the gross output data are pooled from a variety of sources; and second, the data are for the year 2008, which is associated with the financial crisis and documented trade collapse (see Levchenko et al. (2010) and Chor and Manova (2012) among others). Hence, the constructed trade shares may not be representative for the sample of countries analyzed here in a typical year. Moreover, Spain's destination-specific export share may simply be too aggregate of a measure of Mango's effective competition in each country. ${ }^{35}$ Thus, it is reasonable to argue that there is measurement error with respect to the degree of competition that Mango faces in different destinations.

The coefficient estimate on population is negative, as predicted by the model, but it is quantitatively small and only statistically significant at the $10 \%$-level. ${ }^{36}$ The coefficient estimate on sales taxes and tariffs is not statistically different from zero. Neither is the coefficient estimate of the Gini measure of income inequality. The latter may be due to the fact that the Gini coefficient is simply too aggregate of a measure of the differences in income between Mango customers who purchase one versus a bundle of items.

The coefficient estimate of the Euro-currency indicator ranges between -0.17 and -0.18 and it is statistically significant. Hence, denominating prices in the same currency as the source country (Spain) lowers the relative export-to-domestic price by at least 17\%. The result is consistent with a discussion by Pinilla (2007), based on interviews with Mango's management, that price dispersion of Mango products is lower in the Euro zone. Similarly, Cavallo et al. (2014) find that law of one

\footnotetext{
${ }^{35}$ One concern may be that Mango has variable market presence across destinations - solves a different problem across markets - and consequently extracts different mark-ups. The concern is not of first-order importance for two reasons. First, Mango's main competitors, Zara and H\&M, operate in all 29 markets included in the analysis. Second, I verify that Mango's market shares, computed from Mango's sales per market and destination-specific expenditure on apparel and footwear, do not have a statistically significant effect on prices in any of the specifications. These results are available upon request.

${ }^{36}$ Notice that the results on the link between export prices and destination population size do not contradict the findings by Manova and Zhang (2012), Bastos and Silva (2010), Gorg et al. (2010), and Harrigan et al. (2011). The authors demonstrate that export unit values are increasing in destination per-capita income and population, and they argue that differences in product quality can account for the two observations. First, richer countries demand higher quality goods, which sell at a higher price. Second, firms increase product quality but reduce mark-ups in more competitive (larger) markets. Since the present paper examines prices of identical items, all the empirical finding should be interpreted as conditional on product quality being held fixed.
} 
price deviations are significantly larger outside of currency areas for products sold by large retailers such as Zara, H\&M, Apple, and IKEA.

Mango's return and exchange policy also shapes items' prices. Customers who can return items in all the stores in their country of residence pay at least $12 \%$ less for identical goods, while customers who can mail their returns to a local address pay at least $8 \%$ less than others. Hence, Mango charges lower prices or lower shipping and handling fees (or both) in countries where returns are processed locally. The result suggests that, for those countries, Mango incurs lower costs to process returns locally - presumably, the company would not have pursued this return option if it had been less cost efficient. The coefficient estimates for the option to return items in a single store are not statistically different from zero. The same is true for the coefficient estimates associated with the requirement to schedule home pick-ups for returns via mail.

Variance decomposition. Given the differences in magnitudes of the coefficient estimates of several key variables such as per-capita income, DHL costs, Euro-currency indicator, and variables related to Mango's return policy, it is of interest to conduct a variance decomposition exercise that quantifies the contribution of each source to variation in prices. I perform an exercise following the variance decomposition methodology employed by Crucini and Yilmazkuday (2014). I take the variance of both sides of the equation in Section 4.2.1, and then I divide both sides by the variance of the left-hand side, $\operatorname{var}\left(\log \left(p_{j m} / p_{s m}\right)\right)$. By construction, the variance and covariance terms on the right-hand side, scaled by $\operatorname{var}\left(\log \left(p_{j m} / p_{s m}\right)\right)$, will sum to unity. It turns out that the sum of the covariance terms is small, so that up to three quarters of the variation in the relative price is explained by the variances of the regressors, and up to a quarter is accounted for by the variance of the error term. For example, the ratio $\operatorname{var}\left(\hat{\beta}_{y} \log \left(y_{j} / y_{s}\right)\right) / \operatorname{var}\left(\log \left(p_{j m} / p_{s m}\right)\right)$ measures the marginal contribution of the explanatory variable, per-capita income, to the total observed variation in prices across goods and countries.

Across the three regressions that correspond to different measures of market shares, the contribution of per-capita income differences to price variation ranges between $12 \%$ and $23 \%$. DHL shipping costs account for $15 \%$ to $26 \%$, Eurozone membership for $13 \%$ to $15 \%$, and the ability to return items in all local stores for $7 \%$ to $8 \%$ of the price variation. The remaining regressors contribute up to $4 \%$ each. Per-capita income and DHL shipping costs are key contributors to price variations for customers who purchase a single item, which reflects the fact that Mango's shipping charges constitute a large portion of the items' prices in this specification. Given the importance of these costs, in Supplementary Appendix IV, I study the main determinants of DHL's listed shipping prices. DHL (Spain) charges lower prices in both richer and larger markets, and higher prices in markets that are further away from Spain. The facts that DHL prices are lower in richer countries and prices of Mango items are sharply increasing in DHL shipping quotes can reconcile the apparent disconnect between the prices of Mango items and per-capita income in the first plot in Figure 1. After controlling for shipping costs in the empirical analysis, however, the positive relationship between price and per-capita income becomes obvious in Table 5. 


\subsubsection{Robustness Analysis}

I. Additional measures of trade barriers. In the benchmark analysis, I rely on DHL shipping prices to isolate the effect that Mango's shipping costs have on relative prices across countries. One concern is that DHL shipping prices are an incomplete measure of trade barriers. In particular, there may be other forces that shape cross-country trade barriers and are correlated with per-capita GDP, thus biasing the estimated coefficients on income.

To address this issue, I follow the gravity literature and I assume that trade barriers depend on trading partners' geographical and trade-policy attributes. I expand the benchmark specification in two ways. In the first case, I add the third degree polynomial of logged distance between Spain and the destination (in $\mathrm{km}$ ) and indicator variables if the destination is in a regional trade agreement with Spain, if it is landlocked, or if it is an island. In the second, motivated by Eaton and Kortum (2002), I replace the continuous measure of distance with four indicator variables that group countries into distance regions. The distance intervals are (in miles): [0, 750), [750, 1500), [1500,

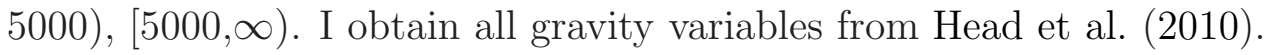

The first three columns in Table 6 report the results from the exercise that uses a continuous (non-linear) distance measure and the last three refer to the estimates obtained using the distance regions. The coefficient estimates on per-capita income and DHL shipping costs are higher compared to the benchmark. Euro membership as well as Mango's return and exchange policy continue to shape price differences across countries. Population size has a negative effect on prices, but the coefficient is precisely estimated only in the specification that relies on distance regions. There is some evidence that countries that share a regional trade agreement with Spain enjoy lower prices.

Geography also plays a role in shaping prices. Prices are lower in landlocked countries and higher on islands. The relationship between price and distance is not robust. Taking the derivative with respect to distance, the coefficient estimates in Table 6 suggest that prices are decreasing in distance for the European countries that are closer to Spain and increasing for the ones that are more distant, only to fall again among the Asian destinations. However, the distance effect can become monotonically increasing by only a slight change in the point estimates. ${ }^{37}$ One reason for this sensitivity is that I have already included a number of indicator variables (such as the Eurozone region or other geographical attributes) as controls in the regression, and these controls make it difficult to measure an independent distance effect. The specification that uses distance regions suggests that prices are significantly higher in region 1, but conveys little information about the remaining distance regions. Given the sensitivity of the results to parameter changes and controls included, I do not make any inferences about the link between price and distance.

Variance decomposition exercises for the six specifications in Table 6 suggest that the median contribution to price variation by per-capita income variation increases to $29 \%$, while the roles of

\footnotetext{
${ }^{37}$ For example, focus on the first column and simply increase the coefficient on logged distance to -44.160 or the coefficient on the square of logged distance to 6.063 - well within the bounds of the confidence intervals around the estimates - and the relationship between price and distance for the sample of 29 countries is strictly increasing.
} 
Table 6: Additional Measures of Trade Barriers: One-Item Purchase, 29 Countries

\begin{tabular}{|c|c|c|c|c|c|c|c|}
\hline & \multicolumn{3}{|c|}{$\frac{\text { Distance Polynomial }}{\text { Market Share Measure }}$} & & \multicolumn{3}{|c|}{ Distance Regions } \\
\hline & tr.shr.ICP & tr.shr.GO & population & & tr.shr.ICP & tr.shr.GO & population \\
\hline pc.gdp & $\begin{array}{l}0.172^{* * *} \\
(0.031)\end{array}$ & $\begin{array}{l}0.184^{* * *} \\
(0.035)\end{array}$ & $\begin{array}{l}0.156^{* * *} \\
(0.043)\end{array}$ & pc.gdp & $\begin{array}{l}0.191^{* * *} \\
(0.034)\end{array}$ & $\begin{array}{l}0.187^{* * *} \\
(0.035)\end{array}$ & $\begin{array}{l}0.138^{* * *} \\
(0.035)\end{array}$ \\
\hline dhl & $\begin{array}{l}0.440^{* * *} \\
(0.068)\end{array}$ & $\begin{array}{l}0.432^{* * *} \\
(0.063)\end{array}$ & $\begin{array}{l}0.412^{* * *} \\
(0.086)\end{array}$ & dhl & $\begin{array}{l}0.412^{* * *} \\
(0.063)\end{array}$ & $\begin{array}{l}0.417^{* * *} \\
(0.064)\end{array}$ & $\begin{array}{l}0.304^{* * *} \\
(0.064)\end{array}$ \\
\hline market.shr & $\begin{array}{l}-0.004 \\
(0.009)\end{array}$ & $\begin{array}{l}-0.008 \\
(0.008)\end{array}$ & $\begin{array}{l}-0.007 \\
(0.012)\end{array}$ & market.shr & $\begin{array}{l}-0.002 \\
(0.008)\end{array}$ & $\begin{array}{c}0.003 \\
(0.006)\end{array}$ & $\begin{array}{l}-0.025^{* *} \\
(0.010)\end{array}$ \\
\hline tax/tariff & $\begin{array}{l}-0.359 \\
(0.653)\end{array}$ & $\begin{array}{l}-0.429 \\
(0.594)\end{array}$ & $\begin{array}{l}-0.086 \\
(0.694)\end{array}$ & tax/tariff & $\begin{array}{l}-0.124 \\
(0.673)\end{array}$ & $\begin{array}{l}-0.010 \\
(0.677)\end{array}$ & $\begin{array}{c}0.770 \\
(0.666)\end{array}$ \\
\hline gini & $\begin{array}{l}-0.147 \\
(0.124)\end{array}$ & $\begin{array}{l}-0.130 \\
(0.121)\end{array}$ & $\begin{array}{l}-0.131 \\
(0.120)\end{array}$ & gini & $\begin{array}{l}-0.133 \\
(0.131)\end{array}$ & $\begin{array}{l}-0.135 \\
(0.133)\end{array}$ & $\begin{array}{l}-0.080 \\
(0.108)\end{array}$ \\
\hline euro & $\begin{array}{l}-0.191^{* * *} \\
(0.034)\end{array}$ & $\begin{array}{l}-0.194^{* * *} \\
(0.033)\end{array}$ & $\begin{array}{l}-0.191^{* * *} \\
(0.035)\end{array}$ & euro & $\begin{array}{l}-0.170^{* * *} \\
(0.031)\end{array}$ & $\begin{array}{l}-0.168^{* *} \\
(0.031)\end{array}$ & $\begin{array}{l}-0.163^{* * *} \\
(0.028)\end{array}$ \\
\hline in.all.stores & $\begin{array}{l}-0.191^{* * *} \\
(0.032)\end{array}$ & $\begin{array}{l}-0.191^{* * *} \\
(0.031)\end{array}$ & $\begin{array}{l}-0.179^{* * *} \\
(0.031)\end{array}$ & in.all.stores & $\begin{array}{l}-0.181^{* * *} \\
(0.028)\end{array}$ & $\begin{array}{l}-0.177^{* * *} \\
(0.030)\end{array}$ & $\begin{array}{l}-0.148^{* * *} \\
(0.028)\end{array}$ \\
\hline in.one.store & $\begin{array}{l}-0.047 \\
(0.046)\end{array}$ & $\begin{array}{l}-0.041 \\
(0.047)\end{array}$ & $\begin{array}{l}-0.039 \\
(0.048)\end{array}$ & in.one.store & $\begin{array}{l}-0.082 \\
(0.070)\end{array}$ & $\begin{array}{l}-0.081 \\
(0.074)\end{array}$ & $\begin{array}{l}-0.082 \\
(0.068)\end{array}$ \\
\hline mail.local & $\begin{array}{l}-0.069^{* *} \\
(0.028)\end{array}$ & $\begin{array}{l}-0.069^{* *} \\
(0.026)\end{array}$ & $\begin{array}{l}-0.069^{* * *} \\
(0.025)\end{array}$ & mail.local & $\begin{array}{l}-0.085^{* * *} \\
(0.026)\end{array}$ & $\begin{array}{l}-0.087^{* * *} \\
(0.025)\end{array}$ & $\begin{array}{l}-0.082^{* * *} \\
(0.020)\end{array}$ \\
\hline home.pick.up & $\begin{array}{l}-0.008 \\
(0.034)\end{array}$ & $\begin{array}{l}-0.021 \\
(0.035)\end{array}$ & $\begin{array}{c}0.014 \\
(0.036)\end{array}$ & home.pick.up & $\begin{array}{l}-0.060^{*} \\
(0.032)\end{array}$ & $\begin{array}{l}-0.054 \\
(0.034)\end{array}$ & $\begin{array}{l}-0.011 \\
(0.028)\end{array}$ \\
\hline landlocked & $\begin{array}{l}-0.087^{* * *} \\
(0.028)\end{array}$ & $\begin{array}{l}-0.086^{* * *} \\
(0.028)\end{array}$ & $\begin{array}{l}-0.079^{* * *} \\
(0.029)\end{array}$ & landlocked & $\begin{array}{l}-0.103^{* * *} \\
(0.023)\end{array}$ & $\begin{array}{l}-0.102^{* * *} \\
(0.022)\end{array}$ & $\begin{array}{l}-0.081^{* * *} \\
(0.022)\end{array}$ \\
\hline island & $\begin{array}{c}0.052^{*} \\
(0.028)\end{array}$ & $\begin{array}{l}0.061^{* *} \\
(0.029)\end{array}$ & $\begin{array}{c}0.051^{*} \\
(0.030)\end{array}$ & island & $\begin{array}{l}0.073^{* *} \\
(0.030)\end{array}$ & $\begin{array}{l}0.068^{* *} \\
(0.032)\end{array}$ & $\begin{array}{l}0.086^{* * *} \\
(0.031)\end{array}$ \\
\hline rta & $\begin{array}{l}-0.058 \\
(0.168)\end{array}$ & $\begin{array}{l}-0.069 \\
(0.163)\end{array}$ & $\begin{array}{c}0.010 \\
(0.184)\end{array}$ & rta & $\begin{array}{l}-0.144^{* *} \\
(0.058)\end{array}$ & $\begin{array}{l}-0.142^{* *} \\
(0.058)\end{array}$ & $\begin{array}{c}-0.093^{*} \\
(0.049)\end{array}$ \\
\hline distance & $\begin{array}{l}-45.160^{* * *} \\
(15.326)\end{array}$ & $\begin{array}{l}-49.218^{* * *} \\
(15.463)\end{array}$ & $\begin{array}{l}-42.763^{* * *} \\
(15.565)\end{array}$ & region 1 & $\begin{array}{l}0.465^{* * *} \\
(0.095)\end{array}$ & $\begin{array}{l}0.445^{* * *} \\
(0.097)\end{array}$ & $\begin{array}{l}0.290^{* * *} \\
(0.100)\end{array}$ \\
\hline distance $e^{2}$ & $\begin{array}{l}5.563^{* * *} \\
(1.875)\end{array}$ & $\begin{array}{l}6.085^{* * *} \\
(1.900)\end{array}$ & $\begin{array}{l}5.224^{* * *} \\
(1.916)\end{array}$ & region 2 & $\begin{array}{c}0.206^{*} \\
(0.113)\end{array}$ & $\begin{array}{c}0.179 \\
(0.120)\end{array}$ & $\begin{array}{l}-0.042 \\
(0.134)\end{array}$ \\
\hline distance $e^{3}$ & $\begin{array}{l}-0.228^{* * *} \\
(0.076)\end{array}$ & $\begin{array}{l}-0.250^{* * *} \\
(0.077)\end{array}$ & $\begin{array}{l}-0.212^{* * *} \\
(0.078)\end{array}$ & region 3 & $\begin{array}{c}0.162 \\
(0.118)\end{array}$ & $\begin{array}{c}0.133 \\
(0.126)\end{array}$ & $\begin{array}{l}-0.088 \\
(0.137)\end{array}$ \\
\hline within $R^{2}$ & 0.687 & 0.688 & 0.687 & & 0.701 & 0.701 & 0.708 \\
\hline
\end{tabular}

The regressand is the price of an item sold by Mango in one of 28 markets, measured relative to the price of the same item sold in Spain, in logs. Regressors and expected signs of coefficients are described in Sections 4.2.1, 4.2.3. $*, * *, * * *$ indicates significance at 10\%,5\%-level, 1\%-level. Standard errors clustered by country in parentheses. Observations: 6860. Fixed Effects: 244 (relative to good 1). Distance interval 4 is numéraire.

DHL shipping costs, Eurozone membership, and the ability to return items at local stores center around $32 \%, 15 \%$, and 14\%, respectively. The remaining variables contribute up to $4 \%$ each. 
II. Alternative Measures of Per-Capita Income. The analysis throughout the main body of the paper relies on nominal per-capita GDP as a measure of per-capita income. In Supplementary Appendix III, I repeat the empirical analysis using five different measures of per-capita income or expenditure: per-capita nominal consumption, household consumption, GNI, GNI measured according to the Atlas method, and PPP-adjusted GDP.

Tables 12-19 in Supplementary Appendix III report the results from the main specification as well as the robustness exercise that includes gravity measures of trade barriers under the assumption of single item purchases using the five alternative measures of per-capita income. The mean and median estimates of the elasticity of price with respect to per-capita income across the 45 different regressions are 0.18 compared to the mean and median estimate of 0.16 obtained using per-capita GDP. The minimum estimate is 0.09 and the maximum is 0.30 . The majority of estimates are statistically significant at the $1 \%$ level. Two of the 45 estimates are statistically significant at the $10 \%$ level and two are not statistically significant. The last four estimates are obtained from regressions that use PPP-adjusted GDP per-capita as a measure of income. Overall, the regressions that use PPP-adjusted GDP yield the weakest and least precise estimates.

DHL shipping costs, Eurozone membership, and the option to return items locally via mail or in store continue to affect prices. In the majority of the specifications, population has a negative and statistically significant effect on prices. The coefficients on import shares are positive and statistically significant in the four benchmark regressions that proxy income by variants of GNI and consumption expenditure, however, the significance disappears once gravity variables are included. Finally, landlocked countries enjoy lower prices, and there is weak evidence that prices are lower for countries that have an RTA with Spain and higher on islands.

Overall, the results that I obtain using various measures of per-capita income strengthen the message that per-capita income differences as well as DHL shipping costs, Eurozone membership, and Mango's return policy shape prices for one-item purchases across countries.

III. Shipping-Cost Minimizers. As described in Section 4.1.1, Mango offers quantity discounts. Since shipping fees typically constitute a third of the price of a single item, it is reasonable to assume that there exist a large set of consumers who purchase just enough so as to receive a shipping discount. Table 2 in Section 4.1.1 shows that consumers in two-thirds of the countries incur no explicit shipping fee above a certain threshold. Therefore, the per-item price that these shipping-cost minimizers pay is equivalent to the web-listed price. One-third of shipping-cost minimizers, however, incur an explicit positive shipping fee. To approximate their effective transaction price, I spread the flat shipping fee for purchases above the threshold over the bundle of goods.

Table 7 repeats the benchmark exercise using transaction prices paid by shipping-cost minimizers. The coefficient estimates on per-capita income are noticeably higher compared to the benchmark exercise that uses transaction prices for single-item purchases. Similar to the benchmark exercise, Eurozone membership has a negative effect on prices of identical goods as does 
Table 7: Robustness Results-Shipping-Cost-Minimizers, 29 Countries

\begin{tabular}{|c|c|c|c|}
\hline & \multicolumn{3}{|c|}{ Market Share Measure } \\
\hline & trade shr (ICP) & trade shr $(\mathrm{GO})$ & population \\
\hline \multirow[t]{2}{*}{ pc.gdp } & $0.204^{* * *}$ & $0.200^{* * *}$ & $0.176^{* * *}$ \\
\hline & $(0.053)$ & $(0.052)$ & $(0.055)$ \\
\hline \multirow[t]{2}{*}{ dhl } & 0.112 & 0.147 & 0.064 \\
\hline & $(0.112)$ & $(0.111)$ & $(0.096)$ \\
\hline \multirow[t]{2}{*}{ market.shr } & 0.003 & 0.011 & -0.019 \\
\hline & $(0.016)$ & $(0.009)$ & $(0.015)$ \\
\hline \multirow[t]{2}{*}{ tax/tariff } & -0.092 & -0.026 & -0.059 \\
\hline & $(0.652)$ & $(0.600)$ & $(0.590)$ \\
\hline \multirow[t]{2}{*}{ gini } & 0.086 & 0.088 & 0.096 \\
\hline & $(0.154)$ & $(0.151)$ & $(0.143)$ \\
\hline \multirow[t]{2}{*}{ euro } & $-0.115^{* * *}$ & $-0.112^{* * *}$ & $-0.126^{* * *}$ \\
\hline & $(0.042)$ & $(0.042)$ & $(0.038)$ \\
\hline \multirow[t]{2}{*}{ in.all.stores } & $-0.135^{* *}$ & $-0.141^{* *}$ & $-0.128^{* * *}$ \\
\hline & $(0.064)$ & $(0.058)$ & $(0.056)$ \\
\hline \multirow[t]{2}{*}{ in.one.store } & -0.056 & -0.073 & -0.021 \\
\hline & $(0.091)$ & $(0.089)$ & $(0.101)$ \\
\hline \multirow[t]{2}{*}{ mail.local } & -0.005 & 0.006 & 0.014 \\
\hline & $(0.037)$ & $(0.035)$ & $(0.036)$ \\
\hline \multirow[t]{2}{*}{ home.pick.up } & 0.012 & 0.032 & 0.045 \\
\hline & $(0.052)$ & $(0.052)$ & $(0.060)$ \\
\hline within $R^{2}$ & 0.405 & 0.411 & 0.415 \\
\hline
\end{tabular}

The regressand is the price of an item sold by Mango in one of 28 destinations, measured relative to the price of the same item sold in Spain, in logs. Regressors and expected signs of coefficients are described in Section 4.2.1. $*, * *, * * *$ indicates significance at 10\%,5\%-level, $1 \%$-level, respectively.

Standard errors clustered by country in parentheses.

Observations: 6860. Fixed Effects: 244 (relative to good 1).

the option to return items in all physical stores. There are two key differences. DHL shipping costs and the requirement to mail returns to a local address no longer play a role in explaining price differences. That DHL shipping costs no longer determine prices reflects the fact that, for purchases above a minimum threshold, the shipping charge constitutes a small fraction of an item's price. In addition, Mango's shipping charges, rather than the items' web-listed prices, likely reflect the company's costs associated with processing returns via mail. This can explain why items that are returned to a local address, which is likely a cheaper option than mailing the items back to Spain, does not have an effect on prices paid by cost minimizers, but significantly lowers prices for single-item purchases. Finally, the $R^{2}$ of the benchmark regressions is higher, which reflects the high explanatory power of DHL shipping costs in accounting for differences in prices paid by customers who purchase a single item over a bundle of goods. Variance decomposition exercises 
Table 8: Additional Measures of Trade Barriers: Shipping-Cost-Minimizers, 29 Countries Distance Polynomial

Market Share Measure

Distance Regions

Market Share Measure

\begin{tabular}{|c|c|c|c|c|c|c|c|}
\hline \multirow{3}{*}{ pc.gdp } & \multirow{3}{*}{$\begin{array}{c}\text { tr.shr.ICP } \\
0.186^{* * *} \\
(0.039)\end{array}$} & \multirow{3}{*}{$\begin{array}{c}\text { tr.shr.GO } \\
0.176^{* * *} \\
(0.041)\end{array}$} & \multicolumn{2}{|l|}{ population } & \multirow{3}{*}{$\begin{array}{c}\text { tr.shr.ICP } \\
0.179^{* * *} \\
(0.044)\end{array}$} & \multirow{3}{*}{$\begin{array}{c}\text { tr.shr.GO } \\
0.171^{* * *} \\
(0.045)\end{array}$} & \multirow{3}{*}{$\begin{array}{c}\text { population } \\
0.138^{* *} \\
(0.054)\end{array}$} \\
\hline & & & $0.136^{* * *}$ & pc.gdp & & & \\
\hline & & & $(0.050)$ & & & & \\
\hline \multirow[t]{2}{*}{ dhl } & 0.112 & $0.133^{*}$ & 0.026 & dhl & 0.026 & 0.043 & -0.049 \\
\hline & $(0.068)$ & $(0.074)$ & $(0.093)$ & & $(0.066)$ & $(0.077)$ & $(0.103)$ \\
\hline \multirow[t]{2}{*}{ market.shr } & -0.015 & 0.007 & $-0.023^{*}$ & market.shr & -0.017 & 0.005 & -0.020 \\
\hline & $(0.010)$ & $(0.009)$ & $(0.013)$ & & $(0.012)$ & $(0.012)$ & $(0.016)$ \\
\hline \multirow[t]{2}{*}{ tax/tariff } & -0.732 & -0.277 & 0.192 & tax/tariff & $-2.232^{* * *}$ & $-1.720^{*}$ & -1.193 \\
\hline & $(0.813)$ & $(0.779)$ & $(0.781)$ & & $(0.818)$ & $(0.951)$ & $(0.982)$ \\
\hline \multirow[t]{2}{*}{ gini } & -0.145 & -0.136 & -0.090 & gini & -0.310 & -0.297 & -0.247 \\
\hline & $(0.185)$ & $(0.186)$ & $(0.162)$ & & $(0.186)$ & $(0.199)$ & $(0.189)$ \\
\hline \multirow[t]{2}{*}{ euro } & $-0.146^{* * *}$ & $-0.141^{* * *}$ & $-0.148^{* * *}$ & euro & $-0.185^{* * *}$ & $-0.177^{* * *}$ & $-0.176^{* * *}$ \\
\hline & $(0.036)$ & $(0.038)$ & $(0.033)$ & & $(0.040)$ & $(0.045)$ & $(0.040)$ \\
\hline \multirow[t]{2}{*}{ in.all.stores } & $-0.212^{* * *}$ & $-0.192^{* * *}$ & $-0.173^{* * *}$ & in.all.stores & $-0.241^{* * *}$ & $-0.219^{* * *}$ & $-0.199 * * *$ \\
\hline & $(0.035)$ & $(0.034)$ & $(0.035)$ & & $(0.038)$ & $(0.039)$ & $(0.042)$ \\
\hline \multirow[t]{2}{*}{ in.one.store } & $-0.191^{* *}$ & $-0.172^{*}$ & $-0.161^{*}$ & in.one.store & -0.098 & -0.078 & -0.077 \\
\hline & $(0.075)$ & $(0.089)$ & $(0.082)$ & & $(0.102)$ & $(0.119)$ & $(0.117)$ \\
\hline \multirow[t]{2}{*}{ mail.local } & -0.010 & -0.019 & -0.011 & mail.local & -0.009 & -0.017 & -0.012 \\
\hline & $(0.040)$ & $(0.037)$ & $(0.034)$ & & $(0.043)$ & $(0.042)$ & $(0.039)$ \\
\hline \multirow[t]{2}{*}{ home.pick.ul } & -0.061 & -0.032 & 0.009 & home.pick.ul & -0.054 & -0.031 & -0.002 \\
\hline & $(0.040)$ & $(0.042)$ & $(0.051)$ & & $(0.038)$ & $(0.042)$ & $(0.050)$ \\
\hline \multirow[t]{2}{*}{ landlocked } & $-0.084^{* *}$ & $-0.079^{* *}$ & -0.058 & landlocked & $-0.092^{* *}$ & $-0.085^{* *}$ & -0.067 \\
\hline & $(0.037)$ & $(0.035)$ & $(0.039)$ & & $(0.037)$ & $(0.037)$ & $(0.043)$ \\
\hline \multirow[t]{2}{*}{ island } & $0.079^{* *}$ & 0.057 & $0.073^{*}$ & island & $0.073^{*}$ & 0.055 & 0.073 \\
\hline & $(0.032)$ & $(0.041)$ & $(0.038)$ & & $(0.042)$ & $(0.052)$ & $(0.050)$ \\
\hline \multirow[t]{2}{*}{ rta } & $-0.337^{* *}$ & -0.284 & -0.117 & rta & $-0.347^{* * *}$ & $-0.335^{* * *}$ & $-0.299 * * *$ \\
\hline & $(0.162)$ & $(0.179)$ & $(0.215)$ & & $(0.066)$ & $(0.074)$ & $(0.077)$ \\
\hline \multirow[t]{2}{*}{ distance } & $-29.563^{*}$ & -22.353 & -21.431 & region 1 & $0.445^{* * *}$ & $0.362^{* * *}$ & 0.257 \\
\hline & $(16.672)$ & $(18.503)$ & (15.758) & & $(0.101)$ & $(0.132)$ & $(0.170)$ \\
\hline \multirow[t]{2}{*}{ distance $e^{2}$} & $3.644^{*}$ & 2.702 & 2.450 & region 2 & $0.503^{* * *}$ & $0.401^{* *}$ & 0.252 \\
\hline & $(2.047)$ & $(2.280)$ & (1.913) & & $(0.132)$ & $(0.180)$ & $(0.222)$ \\
\hline \multirow[t]{2}{*}{ distance ${ }^{3}$} & $-0.150^{*}$ & -0.109 & -0.096 & region 3 & $0.440^{* * *}$ & $0.338^{*}$ & 0.191 \\
\hline & $(0.083)$ & $(0.093)$ & $(0.077)$ & & $(0.141)$ & $(0.190)$ & $(0.223)$ \\
\hline within $R^{2}$ & 0.487 & 0.485 & 0.491 & & 0.479 & 0.475 & 0.479 \\
\hline
\end{tabular}

The regressand is the price of an item sold by Mango in one of 28 markets, measured relative to the price of the same item sold in Spain, in logs. Regressors and expected signs of coefficients are described in Sections 4.2.1, 4.2.3. $*, * *, * * *$ indicates significance at 10\%, 5\%-level, 1\%-level. Standard errors clustered by country in parentheses. Observations: 6860. Fixed Effects: 244 (relative to good 1). Distance interval 4 is numéraire.

suggest that per-capita income differences account for 30\%-40\% of observed price variations; Eurozone membership and the ability to return items at local stores account for up to $8 \%$ and $9 \%$, 
respectively, while DHL shipping costs contribute to only $4 \%$ of the price differences.

The message is similar from the robustness exercises that include gravity proxies for trade barriers (Table 8). Per-capita income differences, Eurozone membership, and the option to return items in physical stores remain the key determinants of price variations across countries. As in the exercises that used prices for single-item purchases, prices are lower in landlocked countries and those that share an RTA with Spain. Finally, the coefficients on the island indicator and the distance variables are closer to zero and much less precisely estimated in the new specification.

Table 20 in Supplementary Appendix III reports the results from the main specification as well as the robustness exercise that includes gravity measures of trade barriers under the assumption that consumers minimize shipping costs using the five alternative measures of per-capita income. ${ }^{38}$ The mean and median estimates of the elasticity of price with respect to per-capita income across the 45 different regressions are 0.18 and all estimates are statistically significant. The minimum estimate is 0.12 and the maximum is 0.28 .

Overall, per-capita income differences, followed by Eurozone membership and Mango's return policy, rather than shipping costs, shape prices paid by customers who bundle their purchases so as to avoid incurring large shipping costs.

IV. Web-Listed Prices. In Supplementary Appendix V, I repeat all the exercises using prices as listed on Mango's website. The results are nearly identical to the ones that I obtain using prices paid by shipping-cost minimizers. The key finding is that the estimates of the elasticity of price with respect to per-capita income are robust across specifications that explicitly account for shipping and handling fees and those that do not. The same is true for the estimates of the coefficients associated with Eurozone membership and the ability to return items in physical stores.

V. Summary The empirical results suggest that Mango customers in the Eurozone and those who enjoy the flexibility to return items in physical stores pay lower prices for identical goods. In addition, Mango extracts higher mark-ups from richer consumers and uses its shipping and handling charge as a vehicle to pass through shipping costs. Across the 162 empirical exercises, whose results are reported in the text and the appendices, the median and mean estimates of the elasticity of price with respect to per-capita income are $0.18 .{ }^{39}$ The 5 th and 95 th percentile estimates amount to 0.12 and 0.24 , respectively. Overall, it is reasonable to conclude that doubling a country's percapita income results in an $18 \%$ percent rise in the price level of apparel and footwear products

\footnotetext{
${ }^{38}$ Due to space constraints, I only report the estimates and associated standard errors of the elasticity of price with respect to per-capita income under the five alternative measures as well as the $R^{2}$ of each regression. The estimates of the remaining coefficients are similar to the ones in Tables 7 and 8 and are available upon request.

${ }^{39}$ For robustness, I re-estimate the model using the Poisson pseudo-maximum-likelihood estimator advocated by Silva and Tenreyro (2006) and I obtain nearly identical results. The finding is due to the fact that the independent variable - price of item abroad relative to home - rarely takes on values below unity and never below 0.9 , since Mango passes through a portion of its shipping cost (which is considerably lower domestically) even to web-listed prices. Thus, taking logs of relative prices yields negligent bias even for the poorest set of countries.
} 
sold via the Internet by Mango. Moreover, given the robust estimates of this elasticity across specifications that reflect different assumptions about transaction prices, it is reasonable to argue that, aside from the shipping and handling charges which are particular to the online store, Mango likely price discriminates on the basis of per-capita income in all outlets.

\section{Quantitative Importance of Variable Mark-ups}

\subsection{Variable Mark-ups: Online VS Offline}

How do price discrimination practices of retailers that operate both online and offline compare to those of standard physical retailers? ${ }^{40}$ This is a difficult question to answer since prices of identical products from physical outlets are not available for a large set of countries. At present, two databases are commonly employed by the existing literature in studies of law-of-one-price deviations: International Comparison Program (ICP) and Economist Intelligence Unit (EIU). The first dataset features sampled retail prices of aggregate good categories made up of products with identical characteristics. The second database features prices of individual goods with identical characteristics sampled across retail locations in cities around the globe. Given the nature of the two datasets, the price observations potentially reflect cross-country differences in mark-ups, product quality, and non-tradable components (such as distribution mark-ups).
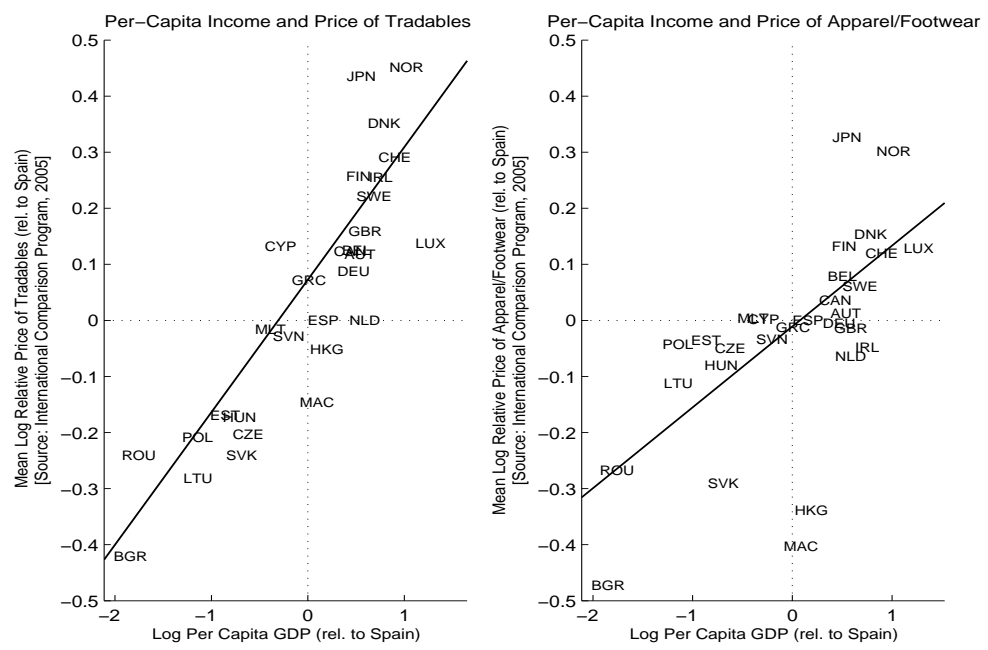

Figure 2: Per-Capita Income and Price in ICP Dataset

In the left panel of Figure 2, I plot the logged price levels of tradable goods from the ICP database against the logged per-capita incomes, relative to Spain, for the 29 countries analyzed

\footnotetext{
${ }^{40}$ Carlton and Chevalier (2001) provide an answer for the US market in year 1999 using prices of fragrances, DVD players, and refrigerators. The authors find that manufacturers that offer products in physical outlets charge higher prices and use various mechanisms to limit distribution online by (competing) Internet retailers who offer deep discounts.
} 
thus far. Following the literature, I compute the price level of tradables as the geometric average of prices of basic headings that correspond to tradable good categories. I use prices of all 62 tradable basic headings from the 2003-2005 round of the ICP and GDP per capita for the year 2004 - the year in which the majority of the prices were collected. ${ }^{41}$ Prices of tradables are higher in countries with higher per-capita incomes. The line of best fit has a slope coefficient of 0.24 , which is statistically significant at the 1\%-level. This result is robust in the literature. Hsieh and Klenow (2007) and Alessandria and Kaboski (2011) find an elasticity of 0.3 using the 1996 ICP data across a large set of countries. The observations in the left panel of the figure, however, span across industries, so it is difficult to relate them to the statistics obtained in this paper. For this reason, in the right panel of the figure, I plot the logged price level of basic headings corresponding to apparel and footwear. The slope of the line of best fit amounts to 0.14 , which is also statistically significant at the 1\%-level. Prices of apparel and footwear products are higher in richer countries, albeit the elasticity estimate is less precise, given that these products span only three of the 62 basic headings that comprise the bundle of tradable goods.

One simple way to assess the importance of variable mark-ups in accounting for variations in retail prices is to apply the econometric model from Section 4.2.1 to ICP data and compare the coefficient estimates to the ones obtained from Mango data. Since Spain is one exporting country among many, products in the ICP dataset do not necessarily originate from and are not shipped from Spain to the different markets. Therefore, a regression framework that controls for Mango's return policy as well as each country's import share of Spanish apparel goods, DHL costs for shipments from Spain, distance from Spain, and free-trade agreement with Spain is not appropriate. The remaining variables used in the exercises in Table 6 above, however, are specific to each market and may be responsible for the observed variation in ICP prices. Consequently, I use these variables for year 2004 to obtain estimates of the elasticity of price with respect to per-capita income from the 2003-2005 ICP data. ${ }^{42}$

Table 9 in Appendix B reports the results using six different measures of per-capita income. The median estimate of the elasticity of price with respect to per-capita income is 0.26 . As in

\footnotetext{
${ }^{41}$ ICP prices are commonly used in the international economics literature. The 2003-2005 database is the latest round of disaggregate price data available to researchers. For example, Simonovska and Waugh (2014a) and Simonovska and Waugh (2014b) use the same set of basic-heading prices to estimate trade elasticities for a large set of countries. I focus on ICP, rather than EIU, data due to the broader country-level coverage of the former. See Crucini and Yilmazkuday (2014) for a detailed analysis of the EIU data.

${ }^{42}$ One notable difference between the ICP and the Mango data analysis is that I separately consider the effect of sales taxes from tariffs in the former. The reason for this modification is that the set of products examined in this exercise is much broader than apparel and the set of sources of origin of the products is potentially the entire world, making it difficult to accurately compute an effective tariff-adjusted tax rate as in the benchmark analysis. I obtain sales tax data for each country for year 2004 from Ernst \& Young. To compute the average tariff for each importer, I obtain applied tariffs (minimum of MFN and effective tariff) for year 2004 at the SITC-4-digit level for each country-pair in the dataset from Feenstra and Romalis (2014). Similarly, I obtain trade flows for year 2004 at the SITC-4-digit level for each country-pair in the dataset from an update to Feenstra et al. (2005) using UN Comtrade data. For each importer, I compute the average tariff as the mean tariff across products and sources, weighted by source- and product-specific imports.
} 
Table 6, which shows results using Mango price data, ICP prices are lower in landlocked countries and higher on islands. Prices are also lower in Eurozone countries, although the coefficient is not precisely estimated. Similarly, prices are lower in countries with higher income inequality, as predicted by extensions of the model in which firms serve customers from different income brackets within a country. As in the case of Mango prices, sales taxes and destination population do not appear to affect ICP prices. A notable difference between the two datasets lies in the fact that tariffs play a very important role in driving ICP price differences; countries with higher average import tariffs experience higher prices of tradables. This result is not surprising in light of the fact that Mango products are exported from Spain to all the destinations, the majority of which do not impose any duties on Spanish imports, while the exporter in the ICP dataset originates from a number of possible countries.

Focusing on apparel and footwear, the signs and magnitudes of the majority of variables are similar to the entire sample of tradables, however, the coefficients on geographic variables are no longer precisely estimated. Notably, the effect of tariffs on prices is much smaller in magnitude and statistically insignificant, which may be due to the fact that the average tariff is not representative of the apparel industry. The median estimate of the elasticity of price with respect to per-capita income is 0.12 . This magnitude is roughly half of that obtained for all tradable goods and is on the lower end of the estimates obtained for Mango apparel products sold via the Internet. Naturally, the statistics in the two datasets reflect different mechanisms: the price elasticity in ICP data may reflect differences in product quality, retail margins, and producers' mark-ups, while the one in the Mango data accounts for producers' mark-ups alone. ${ }^{43}$ Given the comparable magnitudes of the estimate of the price elasticity and the similarities in the behavior of other variables that arise in the two datasets, I conclude that mark-up variations play an important role in accounting for observed differences in retail prices of tradables for the set of 29 countries examined in this paper.

\subsection{Income Differences and Prices of Tradables Around the World}

The empirical exercises in this paper have relied on price data for 29 countries. A natural concern is whether the forces that shape prices of tradables across these countries also account for the majority of price variations around the world. While detailed micro-level price data for a larger sample of countries are not available, ICP prices, shown above to behave similarly to Mango's micro-level

\footnotetext{
${ }^{43}$ Retail margins can be quantitatively large. Crucini and Yilmazkuday (2014) outline a model where retailers in each city import goods and exert effort to distribute them locally in exchange for a wage. In the model, relative prices of goods across cities are falling in relative local retailer productivities and rising in relative local retailer wages and costs of good production and delivery from the factory gate. Assuming that retail wages are uncorrelated with delivery costs and retail productivity, the authors use EIU price data and estimate a large contribution of retailer wages to prices. An interesting extension would include modeling final consumers to have non-homothetic preferences, which would imply that retailers charge mark-ups that vary with city characteristics, most notably per-capita income. In this case, retailer wages could covary with per-capita income; hence, mark-ups would covary with retailer wages, and both would affect prices, so their individual contributions to prices could potentially be evaluated.
} 
prices, do exist. In Table 10 in Appendix B, I repeat the exercise from Table 9 discussed in Section 5.1 above using ICP price data for 54 countries for which sales tax data are available. ${ }^{44}$ The median estimate of the elasticity of the price of all tradables with respect to per-capita income across six different measures of income is 0.18 , roughly $70 \%$ of that found for the 29 countries that span the Mango dataset. Similarly to the previous exercise, prices are higher on islands. Notably, sales tax rather than tariff differences now significantly affect price differences, while the coefficients on the landlocked indicator variable and the Gini measure of inequality are no longer precisely estimated. Overall, the fit of the empirical model, as measured by the R-squared statistic, is somewhat poorer for the larger set of countries.

The empirical model has higher explanatory power for prices of apparel and footwear. The median price elasticity estimate of 0.21 is similar to the case of all tradables and sales taxes continue to play an important role in accounting for price differences. Notable difference can be seen in the lack of statistical significance of the coefficient on the island indicator variable as well as the positive and significant coefficient on the Gini measure. Compared to the sample of countries in the Mango database, in the present and larger sample of countries, the price elasticity estimate is notably higher and taxes play an important role in driving price differences. The latter outcome may be due to the fact that variations in sales taxes are simply far smaller in the Mango sample, where the majority of countries are EU members. The largest difference between the two samples arises in the sign of the Gini coefficient, which is negative in the small sample and positive, albeit less than half in magnitude, in the large sample. The finding in the large sample is consistent with extensions of the model in which firms choose to only serve richer subsets of the population. Hence the differences in signs of the coefficient are plausible if the ICP sample includes apparel and footwear products that are affordable for most consumers in the richer countries that appear in the Mango database, but only to select segments of the population of the notably poorer additional countries that are included in the larger set. However, one cannot exclude the possibility that the difference may be due to measurement error arising from poor data quality, especially among the additional countries that are included in the larger sample.

In a final attempt to assess the empirical model's ability to account for cross-country variations in prices, I repeat the exercise for a set of as many as 107 countries for which all variables, except for sales taxes, are available. ${ }^{45}$ I report the results in Table 11 in Appendix B. The magnitudes of the price elasticity fall for the set of all tradables to a median of 0.13 , roughly $70 \%$ of that found for the 54 countries examined in Table 10, although their statistical significance remains high. Notably, prices are lower in larger markets, as predicted by theory. Finally, the R-squared also falls, which may, among other things, reflect the omission of sales taxes from the specification. ${ }^{46}$

\footnotetext{
${ }^{44}$ See list of countries in Table 29 in Supplementary Appendix VIII.

${ }^{45}$ See list of countries in Table 29 in Supplementary Appendix VIII.

${ }^{46}$ Given the documented importance of sales taxes, one may be concerned that biases may arise in the coefficient estimates of variables that are correlated with sales taxes upon omitting taxes from the specification. To address this concern, I repeat the exercises for the sets of 54 and 29 countries studied above excluding the sales tax variable.
} 
Turning to prices of apparel and footwear, the negative link between prices and population sizes remains. More importantly, the median price elasticity is 0.19 - comparable both to that found in the smaller set of countries examined in Table 10 and to the estimate arising from Mango data. To conclude, the robustness of the magnitude of the elasticity of price with respect to income across different sets of countries yields strong support toward the role that variable mark-ups play in generating a positive relationship between income and prices of tradables around the world.

\section{Conclusion}

In this paper, I argue that firms' variable mark-ups represent a key contributor toward the empirically-documented regularity that tradable consumer goods' prices are systematically positively related to countries' per-capita incomes. On a broader scale, this paper emphasizes the role that income differences play in shaping cross-country price variations in tradable consumption goods as well as in determining aggregate consumption patterns. Since tradable goods that are acquired over the Internet account for an ever increasing portion of consumption bundles of individuals, their prices directly affect consumer welfare. Hence, having obtained an understanding of one of the key mechanisms that affect the behavior of prices across countries, we can further pursue the measurement of welfare of consumers in a world economy linked via the Internet.

\section{References}

Alessandria, G. And J. P. Kaboski (2011): "Pricing-to-Market and the Failure of Absolute PPP," American Economic Journal: Macroeconomics, 3, 91-127.

Alvarez, F. And R. J. Lucas (2007): "General Equilibrium Analysis of the Eaton-Kortum Model of International Trade," Journal of Monetary Economics, 54, 1726-1768.

Baldwin, R. And J. Harrigan (2011): "Zeros, Quality, and Space: Trade Theory and Trade Evidence," American Economic Journal: Microeconomics, 3, 60-88.

Bastos, P. And J. Silva (2010): "The quality of a firm's exports: Where you export to matters," Journal of International Economics, 82, 99-111.

Behrens, K., G. Mion, Y. Murata, and J. Südekum (2014): "Trade, wages, and productivity," International Economic Review, 55, 1305-1348.

Bekkers, E., J. Francois, and M. Manchin (2012): "Import prices, income, and inequality," European Economic Review, 56, 848-869.

I report the results in Tables 27 and 28 in Supplementary Appendix VII. Omitting sales taxes has virtually no impact on coefficient estimates for the set of 29 countries, which is reassuring. In the case of 54 countries, the only notable differences arises for apparel and footwear products, where the omission of taxes biases the coefficients on the Gini variable toward zero. 
Bekkers, E. And I. Simonovska (2015): "The Balassa-Samuelson Effect and Pricing-toMarket: The Role of Strategic Complementarity," Economics Letters, 126, 156-158.

Bertoletti, P. And F. Etro (2013): "Monopolistic competition when income matters," Tech. rep., University of Pavia, Department of Economics and Management.

Burstein, A., J. Neves, And S. Rebelo (2003): "Distribution costs and real exchange rate dynamics during exchange-rate-based stabilizations," Journal of Monetary Economics, 50, 11891214.

Carlton, D. W. And J. A. Chevalier (2001): "Free Riding and Sales Strategies for the Internet," The Journal of Industrial Economics, 49, 441-461.

Cavallo, A., B. Neiman, And R. Rigobon (2014): "Currency Unions, Product Introductions, and the Real Exchange Rate," The Quarterly Journal of Economics.

Chaney, T. (2008): "Distorted Gravity: The Intensive and Extensive Margins of International Trade," American Economic Review, 98 (4), 1707-21.

Chevalier, J. A. And A. K. Kashyap (2011): "Best Prices," Working Paper 16680, National Bureau of Economic Research.

Chor, D. And K. Manova (2012): "Off the cliff and back? Credit conditions and international trade during the global financial crisis," Journal of International Economics, 87, 117-133.

Crucini, M., C. Telmer, and M. Zachariadis (2005a): "Price Dispersion: The Role of Borders, Distance and Location," Carnegie Mellon University, unpublished manuscript.

(2005b): "Understanding European Real Exchange Rates," American Economic Review, $95(3), 724-738$.

Crucini, M. J. And M. Shintani (2008): "Persistence in law of one price deviations: Evidence from micro-data," Journal of Monetary Economics, 55, 629-644.

Crucini, M. J. And H. Yilmazkuday (2014): "Understanding long-run price dispersion," Journal of Monetary Economics, 66, 226 - 240.

De Loecker, J. And F. Warzynski (2012): "Markups and Firm-Level Export Status," American Economic Review, 102, 2437-71.

Eaton, J. And S. Kortum (2002): "Technology, Geography, and Trade," Econometrica, 70 (5), 1741-1779.

Eckel, C. And J. P. Neary (2009): "Multi-Product Firms and Flexible Manufacturing in the Global Economy," Review of Economic Studies, 77, 188-217.

Fajgelbaum, P., G. M. Grossman, and E. Helpman (2011): "Income Distribution, Product Quality, and International Trade," Journal of Political Economy, 119, pp. 721-765.

Feenstra, R. (2010): Product Variety and the Gains from International Trade, MIT Press.

Feenstra, R. And H. MA (2007): "Optimal choice of product scope for multiproduct firms under monopolistic competition," in The Organization of Firms in a Global Economy. 
Feenstra, R. C., R. E. Lipsey, H. Deng, A. C. Ma, And H. Mo (2005): "World trade flows: 1962-2000," Tech. rep., National Bureau of Economic Research.

Feenstra, R. C. And J. Romalis (2014): "International Prices and Endogenous Quality," The Quarterly Journal of Economics, 129, 477-527.

Fieler, A. C. (2011): "Nonhomotheticity and Bilateral Trade: Evidence and a Quantitative Explanation," Econometrica, 79, 1069-1101.

Fitzgerald, D. And S. Haller (2014): "Pricing-to-Market: Evidence From Plant-Level Prices," The Review of Economic Studies, 81, 761-786.

Ghosh, A. And H. Wolf (1994): "Pricing in International Markets: Lessons From The Economist," NBER Working Paper.

Goldberg, P. And F. Verboven (2001): "The Evolution of Price Dispersion in the European Car Market," The Review of Economic Studies, 68 (4), 811-848.

(2005): "Market integration and convergence to the Law of One Price: evidence from the European car market," Journal of International Economics, 65 (1), 49-73.

GoldberG, P. K. And M. M. Knetter (1997): "Goods Prices and Exchange Rates: What Have We Learned?" Journal of Economic Literature, 35, 1243-1272.

Gorg, H., L. Halpern, And B. Murakozy (2010): "Why do within firm-product export prices differ across markets?" Kiel Working Papers 1596, Kiel Institute for the World Economy.

Harrigan, J., X. Ma, And V. Shlychkov (2011): "Export Prices of U.S. Firms," NBER Working Papers 17706, National Bureau of Economic Research, Inc.

Haskel, J. And H. Wolf (2001): "The Law of One Price-A Case Study," Scandinavian Journal of Economics, 103 (4), 545-558.

Head, K., T. Mayer, And J. Ries (2010): "The erosion of colonial trade linkages after independence," Journal of International Economics, 81, 1-14.

Hsieh, C. And P. Klenow (2007): "Relative prices and relative prosperity," American Economic Review, 97, 562-585.

Hummels, D. (2007): "Transportation Costs and International Trade in the Second Era of Globalization," Journal of Economic Perspectives, 21, 131-154.

Hummels, D. And P. J. Klenow (2005): "The Variety and Quality of a Nation's Exports," The American Economic Review, 95, 704-723.

Hummels, D. And V. Lugovskyy (2009): "International Pricing in a Generalized Model of Ideal Variety," Journal of Money, Credit and Banking, 41, 3-33.

Hunter, L. (1991): "The contribution of nonhomothetic preferences to trade ," Journal of International Economics, 30, 345-358.

Hunter, L. And J. Markusen (1988): "Per Capita Income as a Determinant of Trade ," Empirical Methods for International Economics, by R. Feenstra, (MIT Press). 
JACKSON, L. (1984): "Hierarchic Demand and the Engel Curve for Variety." Review of Economics \& Statistics, 66 (1), 8-15.

Johnson, R. C. (2012): "Trade and prices with heterogeneous firms," Journal of International Economics, 86, 43 - 56 .

Kordecka, I. And J. E. Ricart (2009): Mango, Popularizing Fashion, IESE Publishing.

Krugman, P. (1980): "Scale Economies, Product Differentiation, and the Pattern of Trade," The American Economic Review, 70, pp. 950-959.

LACH, S. (2007): "Immigration and Prices," Journal of Political Economy, 115, 548-587.

Lancaster, K. (1979): Variety, Equity, and Efficiency, Columbia University Press.

Levchenko, A., L. Lewis, And L. Tesar (2010): "The collapse of international trade during the 20082009 crisis: in search of the smoking gun," IMF Economic Review, 58, 214-253.

Manova, K. And Z. Zhang (2012): "Export Prices Across Firms and Destinations," The Quarterly Journal of Economics, 127, 379-436.

Markusen, J. R. (2013): "Putting per-capita income back into trade theory," Journal of International Economics, 90, 255 - 265.

Mas-Colell, A., M. Whinston, And J. Green (1995): Microeconomic Theory, Oxford University Press.

Melitz, M. And G. Ottaviano (2008): "Market Size, Trade, and Productivity," Review of Economic Studies, 75 (1), 295-316.

Melitz, M. J. (2003): "The Impact of Trade on Intra-Industry Reallocations and Aggregate Industry Productivity," Econometrica, 71 (6), 1695-1725.

Movshuk, O. (2004): "International Differences in Consumer Preferences and Trade: Evidence from Multicountry, Multiproduct Data," Toyama University, unpublished mimeo.

Pieters, G. (2014): "Trade and Within-Country Consumption Inequality," Trinity University, unpublished manuscript.

Pinilla, J. M. C. (2007): "International Expansion of Mango/MNG," ESIC Business 6 Marketing School, Case Study.

Rose, A. K. (1999): "One Money, One Market: Estimating the Effect of Common Currencies on Trade," NBER Working Papers 7432, National Bureau of Economic Research, Inc.

Sauré, P. (2012): "Bounded Love of Variety and Patterns of Trade," Open Economies Review, $23,645-674$.

Silva, J. M. C. S. And S. Tenreyro (2006): "The Log of Gravity," The Review of Economics and Statistics, 88, 641-658.

Simonovska, I. And M. E. Waugh (2014a): "The elasticity of trade: Estimates and evidence," Journal of International Economics, 92, 34 - 50. 
(2014b): "Trade Models, Trade Elasticities, and the Gains from Trade," Working Paper 20495, National Bureau of Economic Research.

Tirole, J. (1988): The Theory of Industrial Organization, The MIT Press.

Ushchev, P., M. Parenti, And J.-F. Thisse (2014): "Toward a theory of monopolistic competition," ERSA conference papers ersa14p1287, European Regional Science Association.

Verhoogen, E. A. (2008): "Trade, Quality Upgrading, and Wage Inequality in the Mexican Manufacturing Sector," The Quarterly Journal of Economics, 123, 489-530.

Young, A. (1991): "Learning by Doing and the Dynamic Effects of International Trade," The Quarterly Journal of Economics, 106, 369-405.

\section{A Appendix: Theory}

\section{A.1 Consumer Problem and Demand}

The maximization problem of a consumer in $j$, potentially buying varieties from $i=1, \ldots, I$ is

$$
\max _{\left\{q_{i j}^{c}(\omega)\right\}_{i=1}^{I} \geq 0} \sum_{i=1}^{I} \int_{\omega \in \Omega_{i j}} \log \left(q_{i j}^{c}(\omega)+\bar{q}\right) d \omega \quad \text { s.t. } \quad \nu_{j}\left[\sum_{i=1}^{I} \int_{\omega \in \Omega_{i j}} p_{i j}(\omega) q_{i j}^{c}(\omega) d \omega \leq y_{j}\right],
$$

where $\nu_{j}$ is the Lagrange multiplier. The FOCs yield $\left(\forall q_{i j}^{c}(\omega)>0\right)$

$$
\nu_{j} p_{i j}(\omega)=\frac{1}{q_{i j}^{c}(\omega)+\bar{q}}
$$

Let $\Omega_{j} \equiv \sum_{i=1}^{I} \Omega_{i j}$ be the set of all positively-consumed varieties in country $j$. Letting $N_{i j}$ be the measure of set $\Omega_{i j}$, the measure of $\Omega_{j}, N_{j}$, is given by $N_{j}=\sum_{i=1}^{I} N_{i j}$.

For any pair of varieties $\omega_{i j}, \omega_{v j}^{\prime} \in \Omega_{j}$, (a.1) gives

$$
p_{i j}(\omega)\left(q_{i j}^{c}(\omega)+\bar{q}\right)=p_{v j}\left(\omega^{\prime}\right) q_{v j}^{c}\left(\omega^{\prime}\right)+p_{v j}\left(\omega^{\prime}\right) \bar{q}
$$

Integrating over all $\omega^{\prime}{ }_{v j} \in \Omega_{j}$, keeping in mind that the measure of $\Omega_{v j}$ is $N_{v j}$, yields the consumer's demand for any variety $\omega_{i j} \in \Omega_{j}$ 


$$
\begin{aligned}
\int_{\Omega_{j}}\left[p_{i j}(\omega)\left(q_{i j}^{c}(\omega)+\bar{q}\right)\right] d \omega^{\prime} & =\int_{\Omega_{j}}\left[p_{v j}\left(\omega^{\prime}\right) q_{v j}^{c}\left(\omega^{\prime}\right)+p_{v j}\left(\omega^{\prime}\right) \bar{q}\right] d \omega^{\prime}, \\
\Rightarrow\left[p_{i j}(\omega)\left(q_{i j}^{c}(\omega)+\bar{q}\right)\right] \sum_{v=1}^{I} \int_{\Omega_{v j}} 1 d \omega^{\prime} & =\sum_{v=1}^{I} \int_{\Omega_{v j}}\left[p_{v j}\left(\omega^{\prime}\right) q_{v j}^{c}\left(\omega^{\prime}\right)+p_{v j}\left(\omega^{\prime}\right) \bar{q}\right] d \omega^{\prime}, \\
\Rightarrow\left[p_{i j}(\omega)\left(q_{i j}^{c}(\omega)+\bar{q}\right)\right] \sum_{v=1}^{I} N_{v j} & =y_{j}+\sum_{v=1}^{I} \int_{\Omega_{v j}} p_{v j}\left(\omega^{\prime}\right) \bar{q} d \omega^{\prime}, \\
\Rightarrow\left[p_{i j}(\omega)\left(q_{i j}^{c}(\omega)+\bar{q}\right)\right] N_{j} & =y_{j}+\bar{q} P_{j}, \\
\Rightarrow q_{i j}^{c}(\omega) & =\frac{y_{j}+\bar{q} P_{j}}{N_{j} p_{i j}(\omega)}-\bar{q},
\end{aligned}
$$

where $P_{j} \equiv \sum_{v=1}^{I} \int_{\Omega_{v j}} p_{v j}\left(\omega^{\prime}\right) d \omega^{\prime}$ is an aggregate price statistic.

The total demand for variety $\omega$ from $i$ by consumers in $j$ becomes

$$
q_{i j}(\omega)=L_{j}\left[\frac{y_{j}+\bar{q} P_{j}}{N_{j} p_{i j}(\omega)}-\bar{q}\right] .
$$

\section{A.2 Equilibrium: Characterization, Existence, and Uniqueness}

In this section, I rely on the Pareto distribution of firm productivities and characterize the equilibrium objects of the model. I express all objects in terms of wages and I derive a set of equations that solve for the wage rates of all countries simultaneously. I use $v$ as a counter throughout.

Using the optimal price (11), the measure of firms (12), and the conditional density (13) under the Pareto distribution in (14) yields

$$
P_{j}=\sum_{v=1}^{I} J_{v}\left(\frac{b_{v}}{\phi_{v j}^{*}}\right)^{\theta} \int_{\phi_{v j}^{*}}^{\infty} \frac{\tau_{v j} w_{v}}{\left(\phi \phi_{v j}^{*}\right)^{\frac{1}{2}}} \frac{\theta\left(\phi_{v j}^{*}\right)^{\theta}}{\phi^{\theta+1}} d \phi=\sum_{v=1}^{I} J_{v}\left(\frac{b_{v}}{\phi_{v j}^{*}}\right)^{\theta} \frac{\tau_{v j} w_{v}}{\phi_{v j}^{*}} \frac{\theta}{\theta+0.5} .
$$

Then, using (2), (10), and (12) into (a.2) gives

$$
P_{j}=\frac{2 \theta w_{j}}{\bar{q}} .
$$

Moreover, using (a.3) and (10) into (2) yields

$$
N_{j}=\left[\left(\frac{(1+2 \theta) w_{j}}{\bar{q}}\right)^{\theta} \sum_{v=1}^{I} \frac{J_{v} b_{v}^{\theta}}{\left(\tau_{v j} w_{v}\right)^{\theta}}\right]^{\frac{1}{\theta+1}} .
$$

Substituting (a.3) and (a.4) into (10) gives the following expression for the cutoff productivity 


$$
\phi_{i j}^{*}=\tau_{i j} w_{i}\left[\frac{\bar{q} \sum_{v=1}^{I} J_{v} b_{v}^{\theta}\left(\tau_{v j} w_{v}\right)^{-\theta}}{(1+2 \theta) w_{j}}\right]^{\frac{1}{\theta+1}} .
$$

In order to solve the model, it is necessary to jointly determine the wages, $w_{i}$, and the measures of entrants, $J_{i}, \forall i$. The system of equilibrium equations consists of the free entry condition, (16), and the income/spending equality, (17), for each country.

Free entry requires that average profits cover the fixed cost of entry, so

$$
w_{i} f_{e}=\sum_{v=1}^{I}\left(\frac{b_{i}}{\phi_{i v}^{*}}\right)^{\theta} \frac{\bar{q} \tau_{i v} w_{i} L_{v}}{\phi_{i v}^{*}(\theta+1)(2 \theta+1)}
$$

The income/spending identity requires that country $i$ 's consumers spend their entire income on imported and domestically-produced varieties, so

$$
w_{i} L_{i}=\sum_{v=1}^{I} J_{i}\left(\frac{b_{i}}{\phi_{i v}^{*}}\right)^{\theta} \frac{\bar{q} \tau_{i v} w_{i} L_{v}}{\phi_{i v}^{*}(2 \theta+1)} .
$$

Expressions (a.6) and (a.7) yield

$$
J_{i}=L_{i}\left[(\theta+1) f_{e}\right]^{-1}
$$

Substituting (a.8) into (a.5) yields expression (18) for the cutoff productivity in the text.

To characterize wages, use the definition for import shares (23) and trade balance $\sum_{j} T_{i j}=$ $\sum_{j} T_{j i}$ in the definition of income/spending (17) to express income as $w_{i} L_{i}=\sum_{j} T_{i j}=\sum_{j} w_{j} L_{j} \lambda_{i j}$. Finally, in this expression, substitute out import shares using (23) to obtain

$$
\frac{w_{i}^{\theta+1}}{b_{i}^{\theta}}=\sum_{j=1}^{I}\left(\frac{L_{j} w_{j}}{\tau_{i j}{ }^{\theta} \sum_{v=1}^{I} L_{v} b_{v}^{\theta}\left(\tau_{v j} w_{v}\right)^{-\theta}}\right) .
$$

(a.9) implicitly solves for the wage rate $w_{i}$ for each country $i$ as a function of the remaining countries' wages. Rearrange (a.9) and use it to define

$$
Z_{i}(w) \equiv \frac{b_{i}^{\theta}}{w_{i}^{\theta+1}} \sum_{j=1}^{I}\left(\frac{L_{j} w_{j}}{\tau_{i j}{ }^{\theta} \sum_{v=1}^{I} L_{v} b_{v}^{\theta}\left(\tau_{v j} w_{v}\right)^{-\theta}}\right)-1 .
$$

$Z_{i}(w)$ is the $i$-th contribution to the system of $I$ equations that characterizes the equilibrium wage vector. Equilibrium wages satisfy $Z_{i}(w)=0(\forall i)$. It is straightforward to show that there exists a unique equilibrium wage vector that satisfies the system equality, after setting one $w_{i}$ to be a numéraire (see Alvarez and Lucas (2007)). The idea is to treat the system above as an 
aggregate excess demand function of an exchange economy. For existence, it suffices to verify that the system satisfies properties 1-5 listed in Proposition 17.B.2 of Mas-Colell et al. (1995), p. 581. Existence follows from Proposition 17.C.1 of Mas-Colell et al. (1995), p. 585, which is essentially a reference to Kakutani's fixed point theorem. For uniqueness, notice that the system has the gross substitution property (differential version of Definition 17.F.2 in Mas-Colell et al. (1995), p. 612), $\forall i, k, k \neq i, \partial Z_{i}(w) / \partial w_{k}>0$, and the result follows from Proposition 17.F.3 of Mas-Colell et al. (1995), p. 613 .

When gross substitution holds, comparative static exercises with respect to wages are straightforward. Let $B \equiv\left\{\tau_{i j}, L_{j}, b_{i}, \theta\right\}_{i, j=1, \ldots, I}$ denote the set of relevant parameters. Then the equilibrium system can be written as $Z(w ; B)$. Let $w^{*}$ be the unique wage vector corresponding to $B^{*}$; $Z\left(w^{*} ; B^{*}\right)=0$. WLOG, consider a positive productivity shock in country $I$, namely a rise in $b_{I}$. To determine the effect on wages, I need to characterize $D w\left(B^{*}\right)$. By Implicit Function Theorem,

$$
D w\left(B^{*}\right)=-\left[D_{w} Z\left(w^{*} ; B^{*}\right)\right]^{-1} D_{B} Z\left(w^{*} ; B^{*}\right) .
$$

Since the system has the gross substitution property, Proposition 17.G.3 in Mas-Colell et al. (1995), p. 618, ensures that $\left[D_{w} Z\left(w^{*} ; B^{*}\right)\right]^{-1}$ has all its entries negative. Moreover, differentiation shows that $D_{B} Z\left(w^{*} ; B^{*}\right) d b_{I}<<0$ for the first $I-1$ countries (and therefore the sign is positive for country $I)$. Then, $D w\left(B^{*}\right) d b_{I}<<0$ for the first $I-1$ countries. Hence, a positive productivity shock in $I$ lowers the wages of all countries relative to $I$; or, it raises $I$ 's relative wage. A more detailed proof is beyond the scope of the paper and is available upon request.

\section{A.3 Proofs}

In this section, I prove Propositions 1 and 2 and I derive sufficient conditions such that firm sales are strictly increasing in destination population size.

Proof of Proposition 1. Consider expression (22), which represents the price of variety $\phi$ from $i$ in destination $j$ relative to $k, k \neq j$. Since I can always relabel countries, without loss of generality, consider an increase in $w_{j}$, keeping $w_{k}$ fixed. The goal is to show that $\partial\left(p_{i j}(\phi) / p_{i k}(\phi)\right) / \partial w_{j}>0$. Using (18) in (22), it suffices to show that $\partial\left(\phi_{i j}^{*} / \phi_{i k}^{*}\right) / \partial w_{j}<0$.

Using expression (18) for destination $j$ and rewriting the sum in (18) for destination $k$ so as to isolate the $j$-term yields

$$
\frac{\phi_{i j}^{*}}{\phi_{i k}^{*}}=\frac{\tau_{i j}}{\tau_{i k}}\left[\frac{\frac{L_{j} b_{j}^{\theta}}{\tau_{j j}^{\theta} w_{j}^{\theta+1}}+\sum_{v \neq j} \frac{L_{v} b_{v}^{\theta}}{L_{j} b_{j}^{\theta} \tau_{v j} w_{v}}}{\frac{L_{k} \tau_{j k}^{\theta} w_{j}^{\theta}}{w^{\theta}}+\sum_{v \neq j} \frac{L_{v} b_{v}^{\theta}}{w_{k}\left(\tau_{v k} w_{v}\right)^{\theta}}}\right]^{\frac{1}{\theta+1}}
$$

Differentiating (a.10) with respect to $w_{j}$ yields 


$$
\begin{aligned}
& \frac{\partial\left(\phi_{i j}^{*} / \phi_{i k}^{*}\right)}{\partial w_{j}}=\frac{\frac{\tau_{i j}}{\tau_{i k}} \frac{1}{\theta+1}}{\left[\frac{L_{j} b_{j}^{\theta}}{w_{k} \tau_{j k}^{\theta} w_{j}^{\theta}}+\sum_{v \neq j} \frac{L_{v} b_{v}^{\theta}}{w_{k}\left(\tau_{v k} w_{v}\right)^{\theta}}\right]^{2}}\left[\frac{\left.\frac{L_{j} b_{j}^{\theta}}{\tau_{j j}^{\theta} w_{j}^{\theta+1}}+\sum_{v \neq j} \frac{L_{v} b_{v}^{\theta}}{L_{j} b_{j}^{\theta}}+\tau_{v j} w_{v}\right)^{\theta}}{w_{k} \tau_{j k}^{\theta} w_{j}^{\theta}}+\sum_{v \neq j} \frac{L_{v} b_{v}^{\theta}}{w_{k}\left(\tau_{v k} w_{v}\right)^{\theta}}\right]^{\frac{1}{\theta+1}-1}\left[-\frac{L_{j}^{2} b_{j}^{2 \theta}}{\tau_{j j}^{\theta} w_{k} w_{j}^{2 \theta+2} \tau_{j k}^{\theta}} \ldots\right. \\
& \ldots-\frac{L_{j} b_{j}^{\theta}}{\tau_{j j}^{\theta} w_{j}^{\theta+2} w_{k}} \sum_{v \neq j} \frac{L_{v} b_{v}^{\theta}}{\left(\tau_{v k} w_{v}\right)^{\theta}}-\frac{L_{j} b_{j}^{\theta}}{w_{k} w_{j}^{\theta+2} \tau_{j k}^{\theta}} \sum_{v \neq j} \frac{L_{v} b_{v}^{\theta}}{\left(\tau_{v j} w_{v}\right)^{\theta}}-\frac{1}{w_{k} w_{j}^{2}} \sum_{v \neq j} \frac{L_{v} b_{v}^{\theta}}{\left(\tau_{v j} w_{v}\right)^{\theta}} \sum_{v \neq j} \frac{L_{v} b_{v}^{\theta}}{\left(\tau_{v k} w_{v}\right)^{\theta}} \ldots \\
& \left.\ldots-\theta \frac{L_{j} b_{j}^{\theta}}{w_{j}^{\theta+2} w_{k}}\left\{\sum_{v \neq j} \frac{L_{v} b_{v}^{\theta}}{\left(\tau_{j j} \tau_{v k} w_{v}\right)^{\theta}}-\sum_{v \neq j} \frac{L_{v} b_{v}^{\theta}}{\left(\tau_{v j} \tau_{j k} w_{v}\right)^{\theta}}\right\}\right] .
\end{aligned}
$$

A sufficient condition for (a.11) to be strictly negative is that the term in the curly bracket is non-negative. Since, by assumption $\tau_{j j}=1(\forall j)$, the term in the curly bracket is non-negative when trade barriers obey the triangle inequality, $(\forall j, k, v) \tau_{v j} \tau_{j k} \geq \tau_{v k}$.

Proof of Proposition 2. Consider expression (22), which represents the price of variety $\phi$ from $i$ in destination $j$ relative to $k, k \neq j$. Since I can always relabel countries, without loss of generality, consider an increase in $L_{j}$, keeping $L_{k}$ fixed. The goal is to show that $\partial\left(p_{i j}(\phi) / p_{i k}(\phi)\right) / \partial L_{j}<0$. Using (18) in (22), it suffices to show that $\partial\left(\phi_{i j}^{*} / \phi_{i k}^{*}\right) / \partial L_{j}>0$.

Differentiating (a.10) with respect to $L_{j}$ yields

$$
\begin{aligned}
\frac{\partial\left(\phi_{i j}^{*} / \phi_{i k}^{*}\right)}{\partial L_{j}}= & \frac{\frac{\tau_{i j}}{\tau_{i k}} \frac{1}{\theta+1}}{\left[\frac{L_{j} b_{j}^{\theta}}{w_{k} \tau_{j k}^{\theta} w_{j}^{\theta}}+\sum_{v \neq j} \frac{L_{v} b_{v}^{\theta}}{w_{k}\left(\tau_{v k} w_{v}\right)^{\theta}}\right]^{2}}\left[\frac{\frac{L_{j} b_{j}^{\theta}}{\tau_{j j}^{\theta} w_{j}^{\theta+1}}+\sum_{v \neq j} \frac{L_{v} b_{v}^{\theta}}{\left.w_{j} b_{j} \tau_{v} w_{v}\right)^{\theta}}}{w_{k} \tau_{j k}^{\theta} w_{j}^{\theta}}+\sum_{v \neq j} \frac{L_{v} b_{v}^{\theta}}{w_{k}\left(\tau_{v k} w_{v}\right)^{\theta}}\right]^{\frac{1}{\theta+1}-1} \ldots \\
& \ldots \frac{b_{j}^{\theta}}{w_{j}^{\theta+1} w_{k}}\left\{\sum_{v \neq j} \frac{L_{v} b_{v}^{\theta}}{\left(\tau_{j j} \tau_{v k} w_{v}\right)^{\theta}}-\sum_{v \neq j} \frac{L_{v} b_{v}^{\theta}}{\left(\tau_{v j} \tau_{j k} w_{v}\right)^{\theta}}\right\} .
\end{aligned}
$$

A sufficient condition for (a.12) to be strictly positive is that the term in the curly bracket is strictly positive. Since, by assumption $\tau_{j j}=1(\forall j)$, the term in the curly bracket is strictly positive when the trade barriers for $j$ and $k$ obey the triangle inequality, $(\forall v) \tau_{v j} \tau_{j k} \geq \tau_{v k}$, and when the inequality for at least one $v \neq j$ is strict.

Finally, I derive a lower bound on firm productivity such that firm sales are strictly increasing in destination population size. Substituting (18) into (26) and rewriting the sum so as to isolate the $j$-term yields 


$$
\begin{aligned}
r_{i j}(\phi) & =\bar{q}^{\frac{2 \theta+1}{2(\theta+1)}}\left(\tau_{i j} w_{i}\right)^{\frac{1}{2}}\left[(\theta+1) f_{e}(1+2 \theta) w_{j}\right]^{\frac{1}{(\theta+1)}} \ldots \\
& \ldots\left[\frac{\left[(\theta+1) f_{e}(1+2 \theta) w_{j}\right]^{\frac{1}{2(\theta+1)}}}{\bar{q}^{\frac{1}{2(\theta+1)}}\left(\tau_{i j} w_{i}\right)^{\frac{1}{2}}\left[\frac{b_{j}^{\theta}}{\left(\tau_{j j} w_{j}\right)^{\theta} L_{j}^{\theta}}+\sum_{v \neq j} \frac{L_{v} b_{v}^{\theta}}{\left(\tau_{v j} w_{v}\right)^{\theta} L_{j}^{\theta+1}}\right]^{\frac{1}{\theta+1}}}-\frac{1}{\phi^{\frac{1}{2}}\left[\frac{b_{j}^{\theta}}{\left(\tau_{j j} w_{j}\right)^{\theta} L_{j}^{2 \theta+1}}+\sum_{v \neq j} \frac{L_{v} b_{v}^{\theta}}{\left(\tau_{v j} w_{v}\right)^{\theta} L_{j}^{(\theta+1)}}\right]^{\frac{1}{2(\theta+1)}}}\right]
\end{aligned}
$$

Differentiating with respect to $L_{j}$ and using expression (18) obtains

$$
\begin{aligned}
\frac{\partial r_{i j}(\phi)}{\partial L_{j}}= & \frac{\bar{q}^{\frac{2 \theta+1}{2(\theta+1)}}\left(\tau_{i j} w_{i}\right)^{\frac{1}{2}}\left[(\theta+1) f_{e}(1+2 \theta) w_{j}\right]^{\frac{1}{2(\theta+1)}}}{(\theta+1)\left[\sum_{v=1}^{I} \frac{L_{v} b_{v}^{\theta}}{\left(\tau_{v j} w_{v}\right)^{\theta}}\right]^{\frac{2 \theta+3}{2(\theta+1)}}} \ldots \\
& \ldots\left\{\frac{1}{\left(\phi_{i j}^{*}\right)^{\frac{1}{2}}}\left[(\theta+1) \sum_{v \neq j} \frac{L_{v} b_{v}^{\theta}}{\left(\tau_{v j} w_{v}\right)^{\theta}}+\theta \frac{b_{j}^{\theta} L_{j}}{\left(\tau_{j j} w_{j}\right)^{\theta}}\right]-\frac{1}{\phi^{\frac{1}{2}}}\left[(\theta+1) \sum_{v \neq j} \frac{L_{v} b_{v}^{\theta}}{\left(\tau_{v j} w_{v}\right)^{\theta}}+(\theta+0.5) \frac{b_{j}^{\theta} L_{j}}{\left(\tau_{j j} w_{j}\right)^{\theta}}\right]\right\}
\end{aligned}
$$

The term in the curly bracket is strictly positive for highly productive firms, namely, if and only if

$$
\phi>\phi_{i j}^{*}\left[1+\frac{\frac{b_{j}^{\theta} L_{j}}{2\left(\tau_{j j} w_{j}\right)^{\theta}}}{(\theta+1) \sum_{v \neq j} \frac{L_{v} b_{v}^{\theta}}{\left(\tau_{v j} w_{v}\right)^{\theta}}+\theta \frac{b_{j}^{\theta} L_{j}}{\left(\tau_{j j} w_{j}\right)^{\theta}}}\right]^{2} .
$$




\section{B Appendix: ICP Prices}

Table 9: Per-Capita Income and Price of Tradables, ICP 2005, 29 Countries

\begin{tabular}{l|ccccccccc}
\multicolumn{1}{c}{} & \multicolumn{7}{c}{ All Tradable Basic Headings } \\
& pc.income & pop & tax & tariff & euro & landlocked & island & gini & $R^{2}$ \\
\hline gdp & $0.248^{* * *}$ & 0.006 & -0.089 & $3.016^{* * *}$ & -0.060 & $-0.079^{* *}$ & $0.117^{* *}$ & $-0.280^{* *}$ & 0.438 \\
& $(0.025)$ & $(0.012)$ & $(0.443)$ & $(0.944)$ & $(0.043)$ & $(0.034)$ & $(0.055)$ & $(0.114)$ & \\
\hline cons & $0.277^{* * *}$ & -0.007 & -0.168 & $2.917^{* * *}$ & $-0.071^{*}$ & $-0.069^{* *}$ & 0.094 & -0.214 & 0.440 \\
& $(0.028)$ & $(0.012)$ & $(0.465)$ & $(1.009)$ & $(0.041)$ & $(0.029)$ & $(0.058)$ & $(0.129)$ & \\
\hline hh.cons & $0.293^{* * *}$ & -0.009 & 0.035 & $2.573^{* * *}$ & -0.079 & $-0.073^{* * *}$ & 0.086 & $-0.217^{*}$ & 0.442 \\
& $(0.028)$ & $(0.012)$ & $(0.491)$ & $(0.822)$ & $(0.041)$ & $(0.061)$ & $(0.025)$ & $(0.127)$ & \\
\hline gni & $0.249^{* * *}$ & 0.002 & 0.002 & $3.051^{* * *}-0.059$ & $-0.071^{* *}$ & $0.124^{* *}$ & $-0.256^{* *}$ & 0.440 \\
& $(0.025)$ & $(0.012)$ & $(0.451)$ & $(0.925)$ & $(0.042)$ & $(0.030)$ & $(0.056)$ & $(0.120)$ & \\
\hline gni.atl & $0.248^{* * *}$ & 0.001 & 0.112 & $3.372^{* * *}$ & -0.054 & $-0.064^{* *}$ & $0.126^{* *}$ & $-0.271^{* *}$ & 0.441 \\
& $(0.024)$ & $(0.012)$ & $(0.449)$ & $(0.899)$ & $(0.042)$ & $(0.030)$ & $(0.056)$ & $(0.119)$ & \\
\hline ppp.gdp & $0.349^{* * *}$ & 0.027 & -0.279 & $2.402^{* *}$ & -0.037 & $-0.093^{*}$ & $0.161^{* *}$ & $-0.526^{* * *}$ & 0.388 \\
& $(0.057)$ & $(0.017)$ & $(0.653)$ & $(1.130)$ & $(0.054)$ & $(0.055)$ & $(0.068)$ & $(0.151)$ & \\
\hline
\end{tabular}

$\underline{\text { Apparel and Footwear Basic Headings }}$

\begin{tabular}{l|ccccccccc} 
& pc.income & pop & tax & tariff & euro & landlocked & island & gini & $R^{2}$ \\
\hline gdp & $0.109^{* * *}$ & 0.019 & -0.284 & 0.254 & -0.044 & -0.044 & 0.077 & $-0.549^{* * *}$ & 0.591 \\
& $(0.037)$ & $(0.019)$ & $(0.673)$ & $(1.673)$ & $(0.050)$ & $(0.056)$ & $(0.071)$ & $(0.175)$ & \\
\hline cons & $0.127^{* * *}$ & 0.013 & -0.287 & 0.290 & -0.050 & -0.039 & 0.066 & $-0.509^{* * *}$ & 0.599 \\
& $(0.041)$ & $(0.020)$ & $(0.659)$ & $(1.676)$ & $(0.049)$ & $(0.054)$ & $(0.071)$ & $(0.178)$ & \\
\hline hh.cons & $0.133^{* * *}$ & 0.012 & -0.200 & 0.120 & -0.053 & -0.041 & 0.063 & $-0.512^{* * *}$ & 0.599 \\
& $(0.042)$ & $(0.020)$ & $(0.693)$ & $(1.614)$ & $(0.049)$ & $(0.054)$ & $(0.073)$ & $(0.183)$ & \\
\hline gni & $0.110^{* * *}$ & 0.018 & -0.245 & 0.267 & -0.043 & -0.041 & 0.080 & $-0.538^{* * *}$ & 0.592 \\
& $(0.037)$ & $(0.020)$ & $(0.669)$ & $(1.693)$ & $(0.050)$ & $(0.056)$ & $(0.072)$ & $(0.174)$ & \\
\hline gni.atl & $0.109^{* * *}$ & 0.017 & -0.199 & 0.403 & -0.041 & -0.038 & 0.081 & $-0.546^{* * *}$ & 0.592 \\
& $(0.037)$ & $(0.020)$ & $(0.671)$ & $(1.723)$ & $(0.049)$ & $(0.056)$ & $(0.071)$ & $(0.173)$ & \\
\hline ppp.gdp & $0.145^{* * *}$ & 0.029 & -0.422 & -0.141 & -0.032 & -0.051 & 0.095 & $-0.668^{* * *}$ & 0.557 \\
& $(0.068)$ & $(0.021)$ & $(0.728)$ & $(1.659)$ & $(0.054)$ & $(0.060)$ & $(0.076)$ & $(0.171)$ & \\
\hline
\end{tabular}

Regressand: Price level of Basic Heading in each country, relative to price level in Spain, in logs.

$*, * *, * * *$ indicates significance at 10\%, 5\%-level, 1\%-level. Standard errors clustered by country in parentheses.

All Tradable BHs: N. Obs 1736 (Spain is numéraire), Fixed Effects 61 (relative to BH 1).

Apparel/Footwear BHs: N. Obs 84 (Spain is numéraire), Fixed Effects 2 (relative to BH 1). 
Table 10: Per-Capita Income and Price of Tradables, ICP 2005, 54 Countries

All Tradable Basic Headings

\begin{tabular}{l|ccccccccc} 
& pc.income & pop & tax & tariff & euro & landlocked & island & gini & $R^{2}$ \\
\hline gdp & $0.179^{* * *}$ & -0.001 & $0.895^{* *}$ & 0.523 & 0.004 & 0.026 & $0.117^{* * *}$ & 0.052 & 0.365 \\
& $(0.027)$ & $(0.012)$ & $(0.374)$ & $(0.728)$ & $(0.041)$ & $(0.069)$ & $(0.043)$ & $(0.078)$ & \\
\hline cons & $0.188^{* * *}$ & -0.007 & $0.729^{* *}$ & 0.592 & -0.002 & 0.037 & $0.113^{* * *}$ & 0.069 & 0.369 \\
& $(0.027)$ & $(0.011)$ & $(0.358)$ & $(0.689)$ & $(0.041)$ & $(0.068)$ & $(0.042)$ & $(0.074)$ & \\
\hline hh.cons & $0.189^{* * *}$ & -0.007 & $0.816^{* *}$ & 0.411 & 0.000 & 0.041 & $0.110^{* * *}$ & 0.066 & 0.363 \\
& $(0.029)$ & $(0.012)$ & $(0.370)$ & $(0.689)$ & $(0.043)$ & $(0.069)$ & $(0.043)$ & $(0.081)$ & \\
\hline gni & $0.180^{* * *}-0.003$ & $0.943^{* * *}$ & 0.571 & 0.004 & 0.034 & $0.124^{* * *}$ & 0.070 & 0.368 \\
& $(0.026)$ & $(0.011)$ & $(0.367)$ & $(0.726)$ & $(0.040)$ & $(0.067)$ & $(0.043)$ & $(0.077)$ & \\
\hline gni.atl & $0.178^{* * *}-0.002$ & $1.048^{* * *}$ & 0.453 & 0.007 & 0.041 & $0.129^{* * *}$ & 0.075 & 0.366 \\
& $(0.027)$ & $(0.011)$ & $(0.374)$ & $(0.752)$ & $(0.040)$ & $(0.067)$ & $(0.043)$ & $(0.081)$ & \\
\hline ppp.gdp & $0.216^{* * *}$ & 0.008 & $0.970^{* * *}$ & -0.302 & 0.045 & 0.024 & $0.127^{* *}$ & -0.020 & 0.309 \\
& $(0.058)$ & $(0.016)$ & $(0.653)$ & $(0.863)$ & $(0.048)$ & $(0.078)$ & $(0.061)$ & $(0.111)$ & \\
\hline
\end{tabular}

$\underline{\text { Apparel and Footwear Basic Headings }}$

\begin{tabular}{l|clcllcccc} 
& pc.income & pop & tax & tariff & euro & landlocked & island & gini & $R^{2}$ \\
\hline gdp & $0.198^{* * *}$ & -0.014 & $2.312^{* * *}$ & -1.171 & -0.063 & 0.044 & 0.039 & $0.204^{*}$ & 0.721 \\
& $(0.035)$ & $(0.018)$ & $(0.575)$ & $(0.930)$ & $(0.045)$ & $(0.053)$ & $(0.083)$ & $(0.119)$ & \\
\hline cons & $0.215^{* * *}-0.021$ & $2.160^{* * *}$ & -0.943 & $-0.074^{*}$ & 0.059 & 0.034 & $0.233^{* *}$ & 0.742 \\
& $(0.034)$ & $(0.017)$ & $(0.507)$ & $(0.881)$ & $(0.043)$ & $(0.051)$ & $(0.075)$ & $(0.107)$ & \\
\hline hh.cons & $0.221^{* * *}-0.022$ & $2.279^{* * *}-1.069$ & $-0.073^{*}$ & 0.066 & 0.031 & $0.235^{* *}$ & 0.741 \\
& $(0.035)$ & $(0.017)$ & $(0.518)$ & $(0.877)$ & $(0.042)$ & $(0.051)$ & $(0.076)$ & $(0.106)$ & \\
\hline gni & $0.198^{* * *}-0.016$ & $2.359^{* * *}-1.137$ & -0.063 & 0.053 & 0.047 & $0.222^{*}$ & 0.724 \\
& $(0.035)$ & $(0.018)$ & $(0.568)$ & $(0.931)$ & $(0.045)$ & $(0.052)$ & $(0.082)$ & $(0.119)$ & \\
\hline gni.atl & $0.194^{* * *}-0.015$ & $2.463^{* * *}-1.305$ & -0.058 & 0.059 & 0.052 & $0.226^{*}$ & 0.718 \\
& $(0.036)$ & $(0.018)$ & $(0.588)$ & $(0.943)$ & $(0.045)$ & $(0.052)$ & $(0.083)$ & $(0.122)$ & \\
\hline ppp.gdp & $0.262^{* * *}$ & -0.005 & $2.507^{* * *}$ & $-1.762^{* *}$ & -0.023 & 0.048 & 0.051 & $0.142^{* * *}$ & 0.656 \\
& $(0.064)$ & $(0.023)$ & $(0.752)$ & $(1.072)$ & $(0.045)$ & $(0.059)$ & $(0.100)$ & $(0.145)$ & \\
\hline
\end{tabular}

Regressand: Price level of Basic Heading in each country, relative to price level in Spain, in logs.

$*, * *, * * *$ indicates significance at 10\%, 5\%-level, 1\%-level. Standard errors clustered by country in parentheses.

All Tradable BHs: N. Obs 3286 (Spain is numéraire), Fixed Effects 61 (relative to BH 1).

Apparel/Footwear BHs: N. Obs 159 (Spain is numéraire), Fixed Effects 2 (relative to BH 1). 
Table 11: Per-Capita Income and Price of Tradables, ICP 2005, 107 Countries, No Sales Tax

All Tradable Basic Headings

\begin{tabular}{l|clcccccc} 
& pc.income & pop & tariff & euro & landlocked & island & gini & $R^{2}$ \\
\hline gdp & $0.125^{* * *}$ & $-0.031^{* * *}$ & 0.564 & 0.080 & 0.020 & 0.065 & 0.062 & 0.285 \\
& $(0.018)$ & $(0.012)$ & $(0.628)$ & $(0.050)$ & $(0.051)$ & $(0.054)$ & $(0.087)$ & \\
\hline cons & $0.140^{* * *}$ & $-0.029^{* * *}$ & 0.724 & 0.065 & 0.028 & 0.063 & 0.070 & 0.297 \\
& $(0.018)$ & $(0.012)$ & $(0.597)$ & $(0.048)$ & $(0.064)$ & $(0.051)$ & $(0.083)$ & \\
\hline hh.cons & $0.143^{* * *}$ & $-0.030^{* * *}$ & 0.691 & 0.067 & 0.029 & 0.057 & 0.064 & 0.295 \\
& $(0.019)$ & $(0.012)$ & $(0.590)$ & $(0.048)$ & $(0.049)$ & $(0.051)$ & $(0.084)$ & \\
\hline gni & $0.126^{* * *}$ & $-0.032^{* * *}$ & 0.602 & 0.080 & 0.022 & 0.065 & 0.062 & 0.286 \\
& $(0.018)$ & $(0.012)$ & $(0.636)$ & $(0.049)$ & $(0.050)$ & $(0.055)$ & $(0.086)$ & \\
\hline gni.atl & $0.126^{* * *}-0.033^{* * *}$ & 0.565 & $0.083^{*}$ & 0.024 & 0.061 & 0.060 & 0.284 \\
& $(0.019)$ & $(0.012)$ & $(0.628)$ & $(0.050)$ & $(0.051)$ & $(0.055)$ & $(0.087)$ & \\
\hline ppp.gdp & $0.091^{* * *}-0.035^{* *}$ & -0.506 & $0.157^{* * *}-0.048$ & 0.066 & 0.006 & 0.217 \\
& $(0.027)$ & $(0.015)$ & $(0.626)$ & $(0.061)$ & $(0.057)$ & $(0.074)$ & $(0.105)$ & \\
\hline
\end{tabular}

Apparel and Footwear Basic Headings

\begin{tabular}{l|clllllll} 
& pc.income & pop & tariff & euro & landlocked & island & gini & $R^{2}$ \\
\hline gdp & $0.188^{* * *}$ & $-0.031^{*}$ & -0.374 & -0.023 & 0.059 & -0.097 & -0.048 & 0.669 \\
& $(0.021)$ & $(0.017)$ & $(0.783)$ & $(0.048)$ & $(0.053)$ & $(0.072)$ & $(0.086)$ & \\
\hline cons & $0.205^{* * *}$ & $-0.028^{*}$ & -0.216 & -0.041 & 0.066 & -0.101 & -0.040 & 0.686 \\
& $(0.021)$ & $(0.017)$ & $(0.742)$ & $(0.045)$ & $(0.051)$ & $(0.068)$ & $(0.080)$ & \\
\hline hh.cons & $0.211^{* * *}$ & $-0.029^{*}$ & -0.268 & -0.038 & 0.066 & -0.109 & -0.050 & 0.682 \\
& $(0.022)$ & $(0.017)$ & $(0.740)$ & $(0.045)$ & $(0.052)$ & $(0.068)$ & $(0.081)$ & \\
\hline gni & $0.188^{* * *}$ & $-0.032^{*}$ & -0.342 & -0.023 & 0.060 & -0.097 & -0.049 & 0.670 \\
& $(0.021)$ & $(0.017)$ & $(0.791)$ & $(0.047)$ & $(0.053)$ & $(0.072)$ & $(0.085)$ & \\
\hline gni.atl & $0.186^{* * *}-0.034^{*}$ & -0.430 & -0.016 & 0.061 & -0.103 & -0.054 & 0.660 \\
& $(0.022)$ & $(0.018)$ & $(0.780)$ & $(0.048)$ & $(0.054)$ & $(0.073)$ & $(0.089)$ & \\
\hline ppp.gdp & $0.186^{* * *}$ & $-0.037^{*}$ & -1.334 & 0.071 & 0.000 & -0.097 & -0.100 & 0.578 \\
& $(0.033)$ & $(0.021)$ & $(0.836)$ & $(0.053)$ & $(0.060)$ & $(0.094)$ & $(0.105)$ & \\
\hline
\end{tabular}

Regressand: Price level of Basic Heading in each country, relative to price level in Spain, in logs.

$*, * *, * * *$ indicates significance at 10\%, 5\%-level, 1\%-level. Standard errors clustered by country in parentheses. All Tradable BHs: N. Obs 6572 (Spain is numéraire), Fixed Effects 61 (relative to BH 1).

Apparel/Footwear BHs: N. Obs 318 (Spain is numéraire), Fixed Effects 2 (relative to BH 1). 